\title{
Structure of a Single Whisker Representation in Layer 2 of Mouse Somatosensory Cortex
}

\author{
Kelly B. Clancy, Philipp Schnepel, Antara T. Rao, and Daniel E. Feldman \\ Department of Molecular and Cellular Biology and Helen Wills Neuroscience Institute, Biophysics Program, University of California Berkeley, Berkeley, \\ California 94720
}

\begin{abstract}
Layer (L) 2 is a major output of primary sensory cortex that exhibits very sparse spiking, but the structure of sensory representation in L2 is not well understood. We combined two-photon calcium imaging with deflection of many whiskers to map whisker receptive fields, characterize sparse coding, and quantitatively define the point representation in L2 of mouse somatosensory cortex. Neurons within a column-sized imaging field showed surprisingly heterogeneous, salt-and-pepper tuning to many different whiskers. Single whisker deflection elicited low-probability spikes in highly distributed, shifting neural ensembles spanning multiple cortical columns. Whiskerevoked response probability correlated strongly with spontaneous firing rate, but weakly with tuning properties, indicating a spectrum of inherent responsiveness across pyramidal cells. L2 neurons projecting to motor and secondary somatosensory cortex differed in whisker tuning and responsiveness, and carried different amounts of information about columnar whisker deflection. From these data, we derive a quantitative, fine-scale picture of the distributed point representation in L2.
\end{abstract}

Key words: calcium imaging; L2/3; sensory code; sensory map; somatosensory cortex; sparse coding

\section{Introduction}

Layer $(\mathrm{L}) 2$ is a major output of primary sensory cortex to higher cortical areas, and its sensory coding is thus relevant for perception. In rodents, L2 is characterized by very sparse spiking (de Kock et al., 2007; O'Connor et al., 2010b; Barth and Poulet, 2012) and locally heterogeneous (salt-and-pepper) sensory tuning (Ohki et al., 2005; Kerr et al., 2007; Sato et al., 2007; Bonin et al., 2011; Margolis et al., 2012). How these features jointly determine the structure of sensory representation in L2 is unknown. Here, we show that sparse spiking and local tuning heterogeneity lead to a highly distributed, sparse, and shifting cortical point representation (the number and spatial arrangement of neurons that spike in response to a point stimulus), from which different L2 subpopulations sample different sensory information for downstream processing.

We study mouse somatosensory cortex (S1), where each facial whisker is represented by a $\sim 150 \mu \mathrm{m}$ diameter column centered on a L4 "barrel" (Woolsey and Van der Loos, 1970; Lübke and Feldmeyer, 2007). In classical unit recordings, $>80 \%$ of L2/3 neurons are tuned to the column-associated whisker (Simons,

Received Sept. 18, 2014; revised Jan. 7, 2015; accepted Jan. 9, 2015.

Author contributions: K.B.C. and D.E.F. designed research; K.B.C., P.S., and A.T.R. performed research; K.B.C.,P.S., and A.T.R. analyzed data; K.B.C. and D.E.F. wrote the paper.

This work is supported by NIH 1R01NS072416 (D.E.F.) and NSF Graduate Research Fellowship DGE 1106400 (K.B.C). We thank Katie Dorsch Smith, Toshio Miyashita, Alex Naka, and Melissa Newton for help with injections; Keven Laboy, Justin Elstrott, and Amy LeMessurier for comments and analyses; Yuchio Yanagawa for kindly providing GAD67-GFP mice; and Vivek Jayaraman, Rex Kerr, Douglas Kim, Loren Looger, and Karel Svoboda (GENIE Project, Janelia Farm) for generously sharing GCaMP virus.

The authors declare no competing financial interests.

Correspondence should be addressed to Daniel Feldman, Department of Molecular and Cell Biology, 142 LSA No. 3200, UC Berkeley, Berkeley CA 94720. E-mail: dfeldman@berkeley.edu.

DOI:10.1523/JNEUROSCI.3887-14.2015

Copyright $\odot 2015$ the authors $\quad 0270-6474 / 15 / 353946-13 \$ 15.00 / 0$
1978; Armstrong-James and Fox, 1987). However, substantial cross-columnar and paralemniscal input to L2 suggests a more distributed, less topographic organization (Bureau et al., 2006). In $\mathrm{Ca}^{2+}$ imaging experiments, the relative response to two adjacent whiskers, termed two-whisker dominance, is highly variable among neighboring L2/3 neurons (Kerr et al., 2007; Sato et al., 2007; Margolis et al., 2012). This suggests a salt-and-pepper receptive field organization, as in visual (V1) and auditory (A1) cortex (Ohki et al., 2005; Bandyopadhyay et al., 2010; Bonin et al., 2011). However, the true scatter of whisker receptive fields in S1 remains unclear, because prior $\mathrm{Ca}^{2+}$ imaging studies only stimulated 2 whiskers, not the $3 \times 3$ or $4 \times 4$ array needed to fully map S1 receptive fields.

Whisker-evoked spiking in L2 is mostly binary ( 0 or 1 spikes) and strikingly unreliable [mean response probability $(P r), \sim 0.1$ per deflection; Crochet and Petersen, 2006; de Kock et al., 2007], even during behavior (Sachidhanandam et al., 2013). Most neurons have very low $\operatorname{Pr}(<0.1)$ to columnar whisker deflection, with $\sim 10 \%$ of neurons having higher $\operatorname{Pr}(\sim 0.2-0.6)$ and generating most whisker-evoked spikes (O'Connor et al., 2010a). The fine structure of sparse coding within L2/3 remains unclear (Barth and Poulet, 2012), but will strongly impact the point representation on single trials, which is the time scale relevant for perception.

We used two-photon $\mathrm{Ca}^{2+}$ imaging with OGB-1AM (Stosiek et al., 2003; Ohki et al., 2005; Kerr et al., 2007) and deflection of 9-15 whiskers to map whisker receptive fields, $P r$, and the point representation of a single whisker in L2 of S1 in anesthetized mice. We observed markedly heterogeneous whisker tuning among nearby neurons, a spectrum of inherently more- and less-responsive pyramidal cells, and distinct sensory tuning for different L2 output pathways. From these results, we de- 
rived a quantitative picture of the sparse, distributed point representation in L2, with different output pathways sampling distinct information for relay to downstream targets.

\section{Materials and Methods}

All procedures were approved by the University of California Berkeley Animal Care and Use Committee, and follow NIH guidelines. Male mice (P30-P45) were used ( $n=35$ C57BL/6J, 4 GAD67-GFP). GAD67-GFP mice were provided by Yuchio Yanagawa (Tamamaki et al., 2003), bred with C57BL/6J mice, and heterozygous offspring were used for experiments.

OGB-1 AM bolus loading. Mice were anesthetized with urethane (1.2 $\mathrm{g} / \mathrm{kg}$ ) and chlorprothixene $(0.08 \mathrm{mg})$. A stainless steel head holder containing a $7 \mathrm{~mm}$ imaging aperture was affixed over S1. The location of D1-3 whisker columns was mapped through the intact skull using intrinsic signal optical imaging (Grinvald et al., 1986), as by Drew and Feldman (2009). A 1 mm craniotomy was made. $50 \mu$ g OGB-1 AM (Life Technologies) was dissolved in $5 \mu \mathrm{l}$ of $20 \%$ Pluronic F127 in DMSO (Teflabs), and then diluted 10- to 20-fold in buffer (containing the following, in mM: $150 \mathrm{NaCl}, 2.5 \mathrm{KCl}, 10 \mathrm{HEPES}$; Garaschuk and Konnerth, 2010). This solution was pressure ejected ( 3 PSI, $1-5 \mathrm{~min}$ ) from a $3 \mu \mathrm{m}$ tip pipette at $250 \mu \mathrm{m}$ below the pia, centered in the intrinsic signal response area of one whisker. Surface blood vessels were used for alignment. The pipette was removed and dye was allowed to load for $\sim 1 \mathrm{~h}$ before imaging. Typically, cells within $\sim 250 \mu \mathrm{m}$ radius were loaded. A glass coverslip (no. 1 thickness, $7 \mathrm{~mm}$ diameter) was held in place within the imaging aperture via a locking metal ring to minimize brain pulsation.

Retrograde tracer injection. A subset of mice were injected with retrograde tracer in motor cortex (M1) or S1 $\sim 1$ week before calcium imaging. P22-P25 mice were anesthetized with isoflurane, placed in a stereotax, and body temperature was maintained at $37^{\circ} \mathrm{C}$. secondary somatosensory cortex (S2) was localized via intrinsic signal imaging through the intact skull. S2 appeared as a strong intrinsic signal focus lateral to S1, typically at $\sim 1.2 \mathrm{~mm}$ caudal, 4.2 lateral to bregma. M1 was targeted stereotaxically at $1.0 \mathrm{~mm}$ rostrocaudal, $0.7 \mathrm{~mm}$ lateral to bregma (Sato and Svoboda, 2010). A small craniotomy $(\sim 0.5 \mathrm{~mm})$ was opened over either M1 or S2. Two-hundred nanoliters of CTB-AlexaFluor 594 $(10 \mu \mathrm{g} / \mu \mathrm{l}$ in PBS; Life Technologies, C-22842) was injected via a glass pipette (tip diameter $40-60 \mu \mathrm{m}) 500 \mu \mathrm{m}$ below the pia. Injection was performed using a Nanoliter 2000 (WPI) at $20 \mathrm{nl} / \mathrm{min}$ for $10 \mathrm{~min}$, with a 10 min pause before pipette withdrawal to prevent backflow. The scalp was sutured and the animal recovered. Calcium imaging was performed in S1 5-12 d later to allow tracer transport. Injection site location was histologically confirmed after imaging.

GCaMP6 imaging. A small number of experiments were performed with GCaMP6 imaging. P22-P25 mice were anesthetized using isoflurane, placed in a stereotax with body temperature maintained at $37^{\circ} \mathrm{C}$, and a small craniotomy $(0.5 \mathrm{~mm})$ was opened over $\mathrm{S} 1$. To label pyramidal cells, we injected $300 \mathrm{nl}$ of a 50:50 mixture of AAV9.CaMKII0.4.Cre.SV40 and AAV9.Syn.Flex.GCaMP6f.WPRE.SV40 (UPenn Vector Core). After virus injection, the craniotomy was sealed with silicone elastomer (Kwikcast, WPI), the scalp was sutured, and the animal recovered. Two to 3 weeks later, we implanted the imaging head holder, opened a $1-2 \mathrm{~mm}$ craniotomy over S1, and performed calcium imaging as above, under urethane/chlorprothixene anesthesia. Because we did not perform cellattached calibrations of the GCamp6 data, calcium events were detected in GCamp6 imaging by thresholded $\Delta \mathrm{F} / \mathrm{F}$, not deconvolution, using 0.15 $\Delta F / F$ as the threshold for a spike-associated calcium event, as by T. W. Chen et al. (2013).

Two-photon calcium imaging and whisker stimulation. Imaging was performed with a Moveable Objective Microscope (Sutter) and Chameleon Ultra Ti:Sapphire mode-locked laser (Coherent). OGB-1 and AlexaFluor 594 were excited at $800 \mathrm{~nm}$, and GCaMP6f and GFP were excited at $920 \mathrm{~nm}$. Red and green emission were separated with Chroma HQ $525 / 50$ and 575/50 filters and detected with Hamamatsu photomultiplier tubes (H10770PA-40). Using a Nikon objective (16×, 0.8 NA), movies $(100 \mathrm{~s}, 7.23 \mathrm{~Hz}$ frame rate, $128 \times 512$ pixel frame size) were collected using ScanImage (Pologruto et al., 2003). A square area, typically $\sim 160 \times 160 \mu \mathrm{m}$, was imaged. We sampled at lower resolution in the $y$ dimension (fewer pixels per micron) to achieve faster frame rates, and spatially rescaled the images for display. Each field was imaged for $80-$ $120 \mathrm{~min}$, interleaving spontaneous and stimulus-evoked epochs. One to six fields were imaged per mouse.

Whiskers were deflected using a $3 \times 3$ or $4 \times 4$ array of calibrated piezoelectric actuators, each attached to a single whisker. Single rostrocaudal deflections were used ( $4^{\circ}$ amplitude, $4 \mathrm{~ms}$ ramp and return, 100 $\mathrm{ms}$ hold, delivered $3 \mathrm{~mm}$ from skin). Stimuli were delivered at 3-5 s interstimulus interval, interleaved across whiskers. Ramp-hold-return stimuli are commonly used to quantify receptive fields in spiking experiments (Simons, 1978; Simons and Carvell, 1989). We did not explore responses to single-step whisker deflections.

Imaging data analysis. Movies were corrected for slow drift in the $x-y$ plane using TurboReg in ImageJ (Thévenaz et al., 1998). The main source of motion in our images was slow XY drift. The rate of drift was quantified as follows. In a randomly selected subset of data (5 fields from 5 mice), we selected two to three bright astrocytes for reference. We tracked the centroids of these astrocytes frame by frame. The maximum distance between the centroid from one frame to the next never exceeded 1.2 pixels, which is within the effective range for TurboReg motion correction. Over the course of an entire imaging session, the slow drift averaged 7.3 pixels/hour, or 0.0002 pixels/frame. Any frames or movies with severe motion artifacts were excluded from analysis. Less than $2 \%$ of frames were excluded for motion artifacts (range: $0-8 \%$ of frames for a single recording session).

Regions-of-interest (ROIs) were manually selected in ImageJ to include all neuronal somata that appeared in all movies. All other analysis was performed in MATLAB. Traces of relative fluorescence change, $\Delta F / F$, were calculated for each ROI as $\Delta F / F=(F \mathrm{i}-F 0) / F 0$, where $F \mathrm{i}$ is the instantaneous fluorescence value of a cell in one frame, and $F 0$ its average fluorescence value over the preceding $4 \mathrm{~s}$. Positive deconvolution was used to estimate the instantaneous probability of $\mathrm{Ca}^{2+}$ events (Vogelstein et al., 2010) which was thresholded to convert probabilities to a binary event train. A threshold level of 0.18 was used for all cells, and was determined based on cell-attached recordings (see Population Ca2 imaging of single whisker receptive fields in S1 in Results). Spontaneous event rates were determined from deconvolved event trains. Because each whisker stimulus lasted $108 \mathrm{~ms}$, and spikes in L2 can occur with up to $50 \mathrm{~ms}$ latency (Brecht et al., 2003), we considered any event with two frames after the whisker stimulus onset to be a stimulus-evoked response. All reported $P r$ values are whisker-evoked $\mathrm{Pr}-$ spontaneous event rate, unless specified otherwise. All classification of responsive versus unresponsive neurons and whisker tuning are based on net $\mathrm{Pr}$ above spontaneous rate.

Astrocytes were excluded from analysis based on extreme brightness and morphology, as they preferentially take up OGB-1. In a subset of experiments, we included $1 \mu \mathrm{m}$ sulforhodamine in the OGB solution to selectively label astrocytes. We found that astrocytes were clearly identifiable by their brightness, morphology, and calcium dynamics.

Signal-to-noise ratio (SNR) was calculated by dividing the average $\Delta F / F$ over all detected events by the $\mathrm{SD}$ of baseline. To assess the significance of whisker tuning, we calculated $95 \%$ confidence interval (CI) by simulating Poisson-distributed responses to each whisker, based on mean $\mathrm{Pr}$ and actual number of stimulus presentations. Whiskers whose 95\% CI overlapped with the BW were considered equally responsive. For population analysis, neurons with $\mathrm{Pr}_{\mathrm{BW}} \leq 0.05$ were considered unresponsive. Only responsive neurons were included in analyses of tuning width or BW identity. For calculation of mutual information, we compared for each cell a binary vector representing the occurrence of a calcium event on each trial, and a binary vector representing whether the FBW or a different whisker was deflected on each trial. Mutual information was calculated using the MATLAB package mutualinfo (Hanchuan Peng, MATLAB Central File Exchange, retrieved June 5 2014).

In GAD67 mice, GFP-labeled neurons were identified after separating GFP and OGB fluorescence by subtracting an image with $920 \mathrm{~nm}$ excitation (peak GFP excitation); an image with $800 \mathrm{~nm}$ excitation (peak 
OGB-1 excitation). This subtraction was only used to identify GFP+ neurons, and was not carried through the $\Delta F / F$ calculation.

Cell-attached calibration of spike detection. OGB-1 loaded neurons were recorded juxtacellularly under two-photon guidance (Kerr et al., 2007; Sato et al., 2007), using a recording pipette (3 $\mu \mathrm{m}$ tip, 3-5 M $\Omega$ ) filled with fluorescent HEPES-buffered Ringers (in mM: $126 \mathrm{NaCl}, 20$ HEPES, $2.5 \mathrm{KCl}, 2 \mathrm{CaCl} 2,1.3 \mathrm{MgSO}_{4} 14 \mathrm{D}(+)$ Glucose, 50 AlexaFluor 594, pH 7.3, $290 \mathrm{mOsm}$ ). A loose seal configuration was obtained, and spike-associated currents were measured in voltage-clamp mode with holding potential adjusted to maintain a holding current of $0 \mathrm{pA}$. Spikes from the loose seal recording were collected simultaneous to OGB imaging with Ephus software (Suter et al., 2010). Spike times were binned into imaging frames, taking into account the scan time of each cell within the imaging frame. A spike in the same frame as a calcium event was considered a successful detected spike. A false alarm was a calcium event without a corresponding spike. We based all $\operatorname{Pr}$ and spontaneous rate measurements on the binary occurrence of a calcium event in each frame or stimulus response window.

Histological localization of imaging fields relative to anatomical barrels. In a subset of experiments, imaging fields were localized relative to anatomical boundaries of whisker-related barrel columns. To do this, lowpower images of the calcium imaging field and surrounding surface blood vessels were obtained on the two-photon microscope. The mouse was anesthetized with isoflurane and killed, and then the brain was removed, fixed with $4 \%$ paraformaldehyde, and flattened. One-hundredfifty micrometer-thick tangential sections were cut, preserving the surface blood vessels, and stained for cytochrome oxidase activity to reveal L4 barrels. Barrel boundaries were projected onto the surface vessel map, which was then aligned to the low-power images of the calcium imaging field (Golshani et al., 2009; Knott et al., 2009).

Tetrode recording. Extracellular recordings were made with custommade dual tetrodes (12.5 $\mu \mathrm{m}$ nichrome wire, $0.3-1.5 \mathrm{M} \Omega$ ). Signals were preamplified (20×, Plexon Instruments), bandpass filtered $(0.3-8 \mathrm{kHz})$, further amplified $(50 \times)$, and digitized at $31.25 \mathrm{kHz}$. Signals were acquired continuously. Single units were isolated offline using Ultra Mega Sort 2000 (Hill et al., 2011). Spike waveforms (1.5 ms) were aligned, overclustered using hierarchical clustering, and aggregated into statistically distinct clusters. Clusters were manually evaluated for separability in amplitude and principal component space. We required $<0.5 \%$ refractory period violations (interspike interval $<1.5 \mathrm{~ms}$ ) and $<30 \%$ missed spikes (estimated by comparing spike detection threshold with Gaussian-fitted distribution of spike amplitude). L2/3 recordings were made at 163-408 $\mu \mathrm{m}$ depth. Fast-spiking (FS) units were identified by peak-to-trough time of the spike waveform $(<0.6 \mathrm{~ms}$; Gabernet et al., 2005) and excluded from analysis. Spontaneous and evoked firing rates were calculated over $50 \mathrm{~ms}$ before and after stimulus onset, respectively.

Simulation of the cortical point representation. We simulated whisker responses in nine adjacent cortical columns of 100 neurons each. Neural tuning and Pr for each simulated neuron was drawn randomly from response statistics of imaged neurons from all nine whisker experiments combined. Neurons were spatially arranged within columns based on their whisker tuning to match the subcolumnar topography reported by Sato et al. (2007). No explicit gradient of Pr, or map of direction selectivity was included (Kerr et al., 2007; Kremer et al., 2011). We simulated responses to 50 trials of rostral deflection of the whisker corresponding to the central column. A Poisson-generated spike train was generated for each neuron based on its whisker receptive field and Pr. The simulation shows predicted spiking over spontaneous rate.

\section{Results}

Population $\mathrm{Ca}^{2+}$ imaging of single whisker receptive fields in $\mathrm{S} 1$

We imaged whisker-evoked activity in populations of L2 neurons in mouse $\mathrm{S} 1$ by bolus injecting the calcium indicator OGB-1AM (Stosiek et al., 2003; Ohki et al., 2005; Kerr et al., 2007; Sato et al., $2007)$ into a functional whisker-related column (C1-3, D1-3, or E1-2) identified by intrinsic signal imaging (Grinvald et al., 1986). Activity was measured using two-photon imaging in
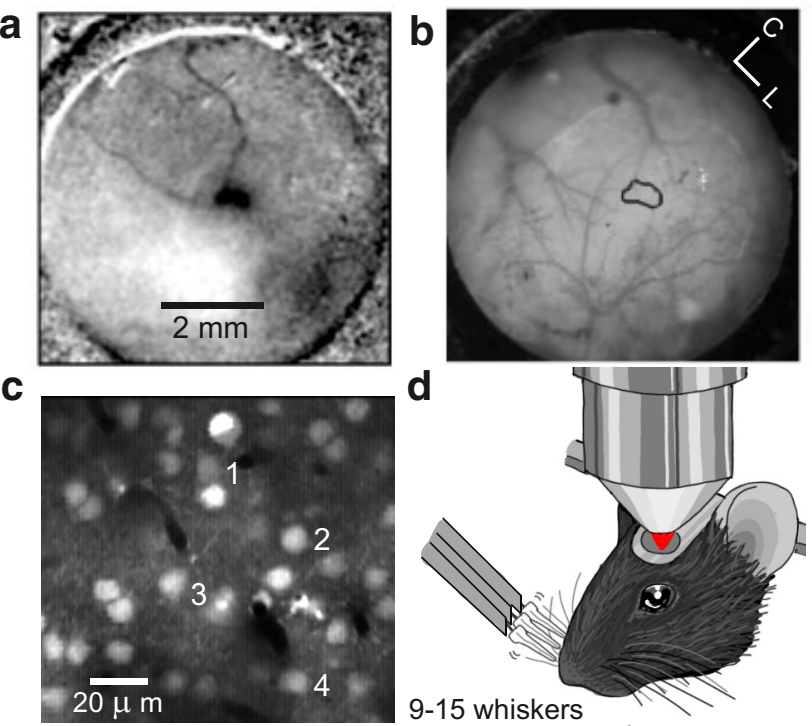

9-15 whiskers

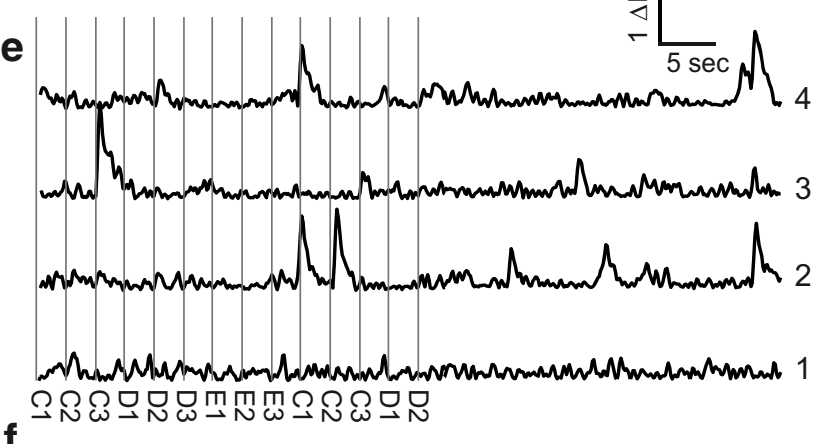

f

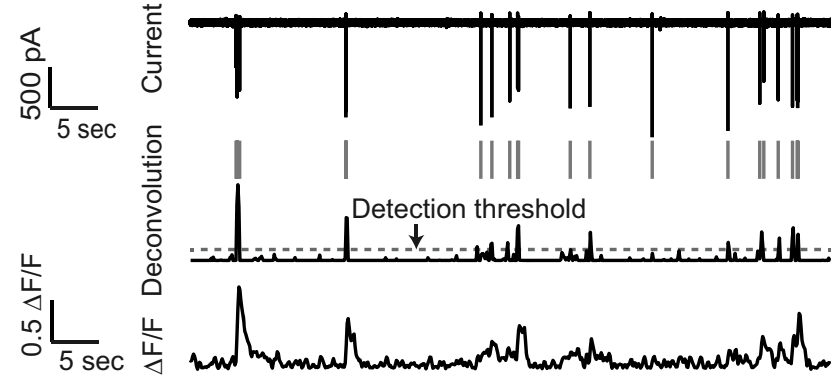

Figure 1. Ensemble calcium imaging in S1 in vivo. $\boldsymbol{a}, \boldsymbol{b}$, Intrinsic signal imaging of $D 2$ whisker response area used to target $0 G B-1 A M$ injection. Imaging is through the intact skull within the $7 \mathrm{~mm}$ head-plate imaging well. c, Example imaging field loaded with OGB-1AM. d, Whisker stimulation during imaging. $e, \Delta F / F$ traces for four neurons labeled in c. Gray lines, individual whisker deflections. Right half of traces show spontaneous activity epoch. $\boldsymbol{f}$, Calibration of calcium imaging sensitivity for one neuron. Bottom, $\Delta F / F$ trace. Middle, Deconvolution output showing instantaneous probability of a $\mathrm{Ca}^{2+}$ event, thresholded to yield a calcium event train (gray). Top, Simultaneous cell-attached recording of spikes.

20-50 neurons in a $\sim 160 \times 160 \mu \mathrm{m}$ field (approximately the size of an anatomical whisker column), at 120-180 $\mu \mathrm{m}$ depth corresponding to L2 (Lefort et al., 2009). Whisker stimuli were single, interleaved deflections of nine or 15 neighboring whiskers in a $3 \times 3$ or $4 \times 4$ array (Fig. $1 a-e$ ). Discrete calcium events corresponding to spikes or spike bursts were identified from $\Delta F / F$ traces by non-negative deconvolution (Vogelstein et al., 2010). The sensitivity of spike detection was calibrated by simultaneous cell-attached recording ( $n=15$ cells; Fig. $1 f$; see Materials and Methods). Deconvolution detected $55 \%$ of single spikes (within $140 \mathrm{~ms}$, a single imaging frame) and $92 \%$ of spike doublets, with 
Table 1. Mean spike detection and false-positive rates from cell-attached recordings during imaging

\begin{tabular}{llrl}
\hline \multirow{2}{*}{$\begin{array}{l}\text { Detected calcium events/ } \\
\text { imaging frame }\end{array}$} & \multicolumn{3}{l}{$\begin{array}{l}\text { Detected spikes from cell-attached recordings, } \\
\text { \% }(n=15 \text { cells })\end{array}$} \\
\cline { 2 - 4 } & 1 & $2+$ & 0 \\
\hline 1 & 55 & 92 & 11 \\
0 & 45 & 8 & 89 \\
\hline
\end{tabular}

a false-positive rate of $0.01 \mathrm{~Hz}$ or $11 \%$ of all spontaneous calcium events (Table 1). This corresponds to a false-positive rate of 0.03 events per stimulus presentation window.

We measured OGB-derived $\mathrm{Ca}^{2+}$ events for all neurons in each imaging field during whisker stimulation and interleaved epochs of spontaneous activity. For each neuron, we quantified whisker-evoked response probability $(P r)$ for each whisker, and identified the best whisker (BW) as the whisker that evoked the highest Pr. All Pr values are net evoked Pr after subtraction of the spontaneous event rate for each neuron (see Materials and Methods). The most common BW across neurons in an imaging field was designated the field best whisker (FBW). Post hoc reconstruction of imaging field location relative to the anatomical barrels in layer 4 showed that FBW identity matched anatomical barrel identity in the imaging field center in eight of eight cases (see below).

\section{Highly heterogeneous whisker tuning in a single cortical column}

We measured whisker tuning to nine or 15 whiskers (50-150 repetitions each), unlike prior studies that used only one to two whiskers (de Kock et al., 2007; Kerr et al., 2007; Sato et al., 2007; Sato and Svoboda, 2010). Whisker stimuli were interleaved, so that each whisker was only deflected every $27-45 \mathrm{~s}$. This resulted in negligible habituation (paired t test, responses during first half of recording versus second half of each session, $p=0.78$ ). L2 neurons showed remarkable local heterogeneity in somatotopic whisker tuning, measured as mean $P r$ to each sampled whisker. Figure $2 a-c$ shows an example imaging field in which D2 was the FBW, but that contained numerous strongly responsive neurons tuned to E1, E2, D1, D2, D3, C1, and C2 whiskers. Tuning was usually sharp and statistically significant, as verified by calculating 95\% confidence intervals for $P r$ for each whisker, assuming Poisson statistics (Fig. 2d). Many cells were driven by the BW significantly more than any other whisker, whereas other cells had statistically equal responses to several neighboring whiskers (Fig. $2 d$ ). Tuning heterogeneity was also evident in average $\Delta F / F$ traces without deconvolution (Fig. $2 c, e$ ). We also confirmed divergent tuning using the genetically encoded calcium indicator GCaMP6f (T. W. Chen et al., 2013; data not shown, and not included in subsequent analyses).

A subset of imaging fields were reconstructed relative to anatomical column boundaries determined by cytochrome oxidase (CO) staining of L4 barrels ( $n=8$ fields). Neurons tuned to noncolumnar whiskers were located throughout the whisker column, not just over column edges (Fig. 3).

We quantified the diversity of whisker tuning across all imaging fields ( 1659 neurons, assayed with either nine whiskers ( 46 fields, 24 mice) or 15 whiskers ( 5 fields, 3 mice; Fig. 4). Twenty-five percent of neurons (422) were tuned to the FBW, 11\% to same-row, adjacentarc whiskers (181), 12\% to same-arc, adjacent-row whiskers (195), and $11 \%$ to adjacent-arc, adjacent-row ("diagonal") whiskers (185). Nineteen percent were tuned to more distant whiskers, and 22\% of neurons were unresponsive to all presented stimuli (defined as $\operatorname{Pr}<$ 0.05; see Materials and Methods; Fig. 4a,b).
Whisker receptive fields of individual neurons were narrow, on average, with immediate surround whiskers evoking $38 \pm 3 \%$ Pr compared with the BW (Fig. 4c). Whisker tuning of entire imaging fields (compiled across all cells) was much broader, with whiskers immediately adjacent to the FBW evoking $65 \pm 5 \% \mathrm{Pr}$ compared with the FBW (Fig. 4d). To compare tuning width statistically, we calculated whisker selectivity index (WSI), defined as $\operatorname{Pr}$ to the best whisker (for 1 neuron or the entire field) divided by the average Pr to immediately neighboring whiskers. WSI was significantly greater for single neurons than for fields ( $p=3.5 \mathrm{e}-21$, Wilcoxon rank sum test; Fig. 4e). Thus, local fields are composed of individual neurons with somatotopically heterogeneous whisker tuning.

Neurons sharing the same BW were spatially scattered across each imaging field, but could potentially share inputs from common excitatory subnetworks (Ko et al., 2011; Harris and Mrsic-Flogel, 2013). We tested whether cotuned neurons share functional inputs by measuring the correlation between calcium event trains for pairs of neurons during spontaneous activity periods. Across all neurons, pairwise correlations fell off with distance between neurons; however, neurons tuned to the same BW showed higher correlations than neurons tuned to different BWs (Fig. 4f). This finding is similar to results in visual and motor cortex (Komiyama et al., 2010; Ch'ng and Reid, 2010; Ko et al., 2011), and suggests that cotuned neurons are organized into distinct subnetworks.

\section{Skewed distribution of more-responsive and less-responsive neurons}

Pr to the FBW $\left(P_{\mathrm{FBW}}\right)$ was low, and skewed across the L2 neuron population: mean $P r_{\mathrm{FBW}}$ was 0.09 (Fig. $5 a$, solid curve), and $35 \%$ of neurons were unresponsive to FBW (defined as $\operatorname{Pr}_{\mathrm{FBW}}<0.05$ ). This confirms prior studies that showed weak whisker responses in L2/3 with a small tail of more responsive neurons (de Kock et al., 2007; Kerr et al., 2007; Sato et al., 2007; Crochet et al., 2011). Our average $P r$ is weaker than a prior study (Sato et al., 2007) because we include all cells, not just responsive cells, in the distribution. Responsiveness of each neuron to its individually determined BW $\left(\operatorname{Pr}_{\mathrm{BW}}\right)$ was somewhat stronger: mean $\operatorname{Pr}_{\mathrm{BW}}$ was 0.12 , and only $16 \%$ of neurons were unresponsive (Fig. $5 a$, dashed curve). Thus, $\operatorname{Pr}$ was $33 \%$ greater when assayed with the individually determined best whisker, but was still quite low overall. The $\operatorname{Pr}_{\mathrm{BW}}$ distribution was skewed both before and after subtracting each neuron's spontaneous firing rate (Fig. $5 a$, bars). All results outside of Figure $5 a$ are based on $\operatorname{Pr}_{\mathrm{BW}}$ with spontaneous firing rate subtracted.

Because only $55 \%$ of single spikes were detected by OGB-1 imaging, the absolute $\operatorname{Pr}$ values reported here likely underestimate true $P r$, and the $16 \%$ of unresponsive neurons $(\operatorname{Pr}<0.05)$ may actually respond up to $\operatorname{Pr}=0.09$. Incomplete spike detection may also explain why our $\operatorname{Pr}$ distribution is less skewed than observed in extracellular or juxtacellular recordings (Hromádka, 2008; Sakata and Harris, 2009; O’Connor et al., 2010b).

\section{Point representation of a single whisker deflection in L2}

We calculated the cortical point representation of a single whisker deflection, based on the spatial spread of neurons tuned to each whisker, receptive field width for individual neurons, and whisker-evoked Pr. In the average imaging field, $25 \%$ of neurons were tuned to the FBW and 3-6\% were tuned to any one single immediately adjacent row, arc, or diagonal whisker (Fig. 5a). Thus, the set of neurons cotuned to one whisker (here called the tuning ensemble) is distributed across columns. A much larger 
a

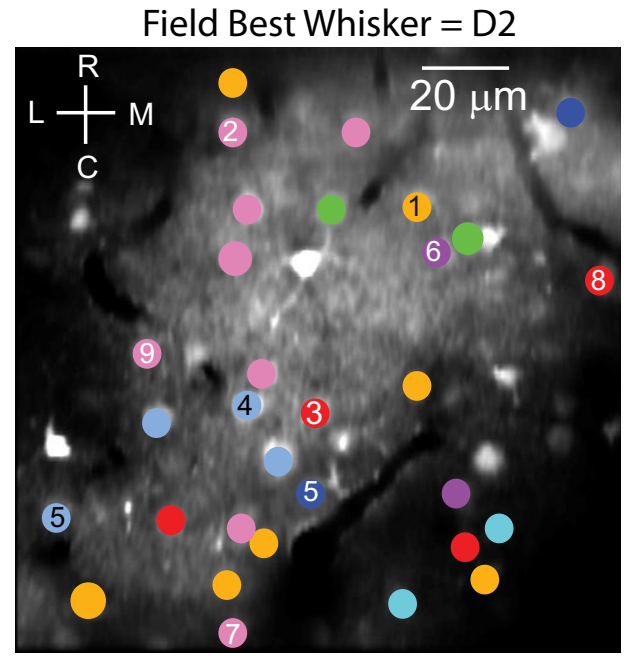

b
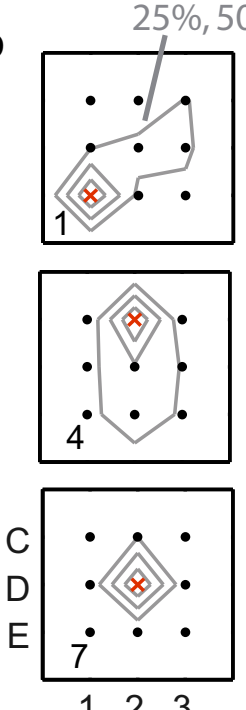

C

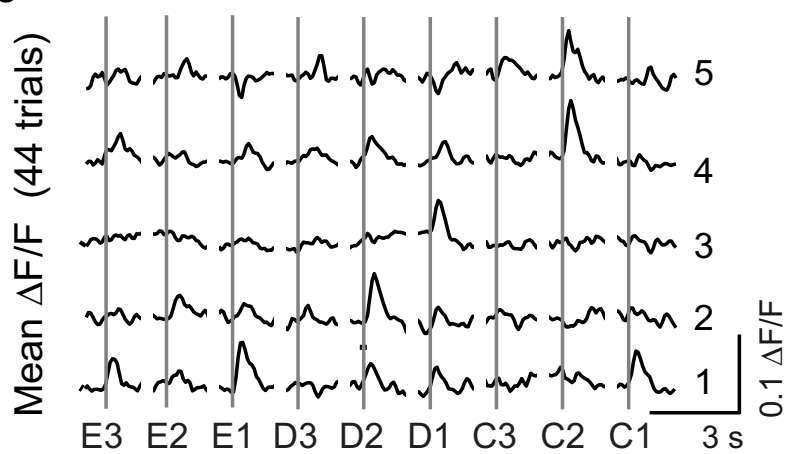

d
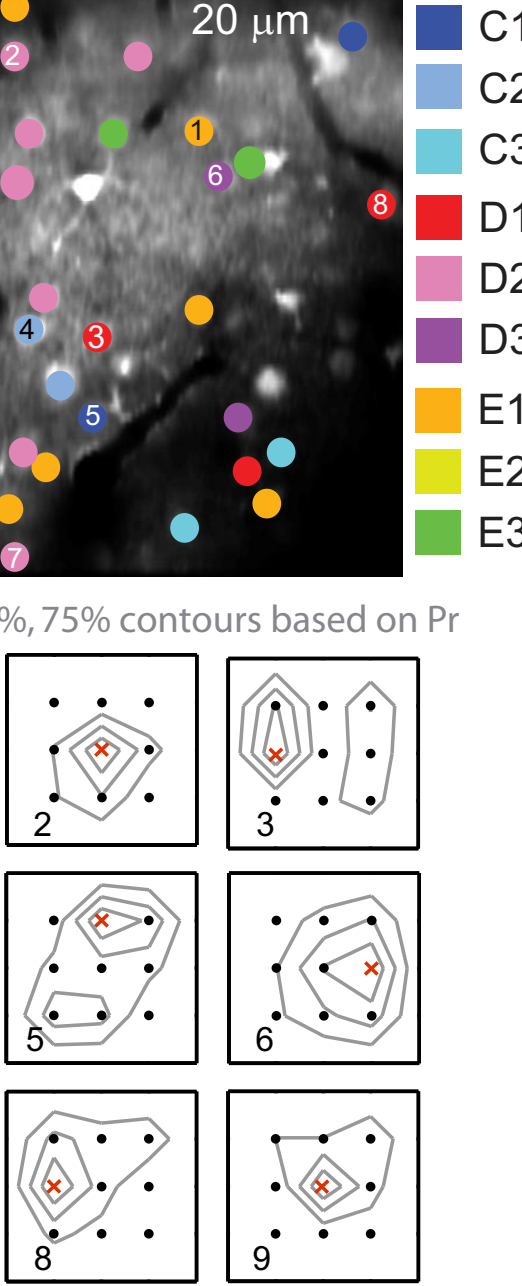

e

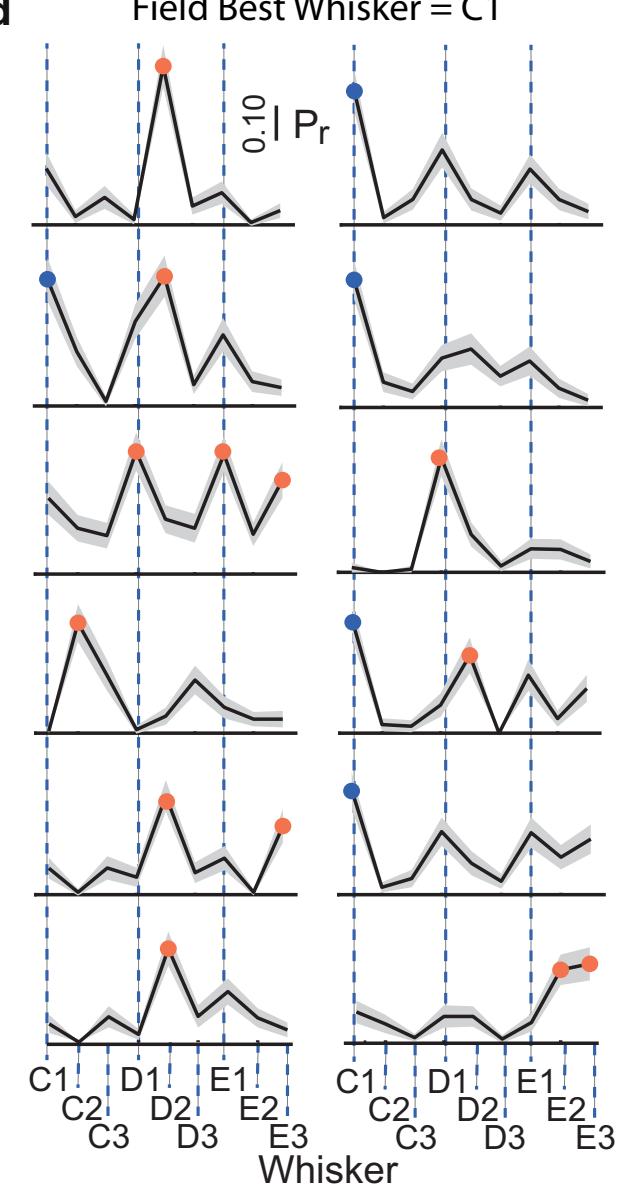

Field Best Whisker $=\mathrm{C} 2$

$75 \%$ contour based on peak $\Delta \mathrm{F} / \mathrm{F}$
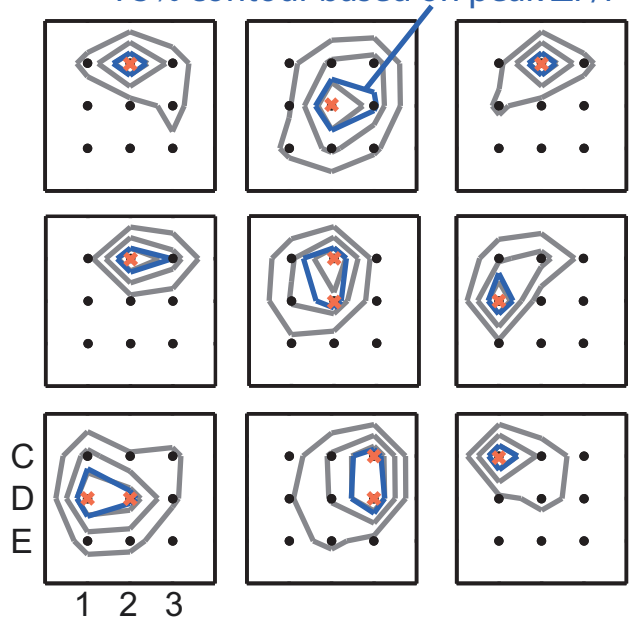

Figure 2. Heterogeneous whisker tuning among $L 2$ neurons. $\boldsymbol{a}-\boldsymbol{c}$, One example imaging field in a D2 whisker column. $\boldsymbol{a}$, All neurons, with color indicating BW. $\boldsymbol{b}$, Tuning curves for the nine most responsive neurons. Gray contours denote 25,50 , and $75 \%$ of maximum Pr. Crosses mark BW and all whiskers with statistically indistinguishable Pr from the BW. $c$, Mean whisker-evoked $\Delta$ F/F for five most responsive neurons. $\boldsymbol{d}$, Whisker tuning for the 12 most responsive cells in one imaging field in a $\mathrm{C} 1$ whisker column. Shading shows $95 \%$ confidence interval for mean Pr, assuming Poisson statistics. Circles mark the BW and all whiskers with Pr statistically indistinguishable from the BW. Blue, C1 whisker; red, non-C1 whiskers. $\boldsymbol{e}$, Whisker tuning for the nine most responsive cells in another field, where FBW was C2. Gray contours as in $\boldsymbol{b}$. Blue contours show $>75 \%$ of maximum peak $\Delta F / F$ (without deconvolution). The close agreement of blue and gray contours shows that heterogeneous whisker tuning is not an artifact of the deconvolution method.

fraction of neurons in each field was at least minimally responsive $(\operatorname{Pr}>0.05)$ to the FBW (58\%) or to any one single adjacent row, arc, or diagonal whisker (41-44\%). We call this the minimally responsive ensemble. Because Pr was very low for most neurons, a much smaller fraction of neurons spiked, on average, to a single trial of FBW deflection $(6.8 \%)$ or the other whiskers (4.8-5.1\%). We call this the single-trial spiking ensemble, and it was spatially broader than the tuning ensemble. Because we detected only $55 \%$ 
a

b
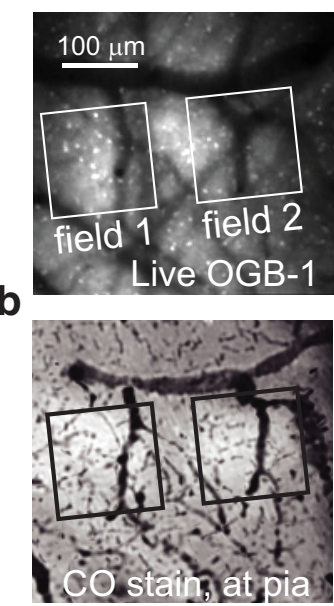

c

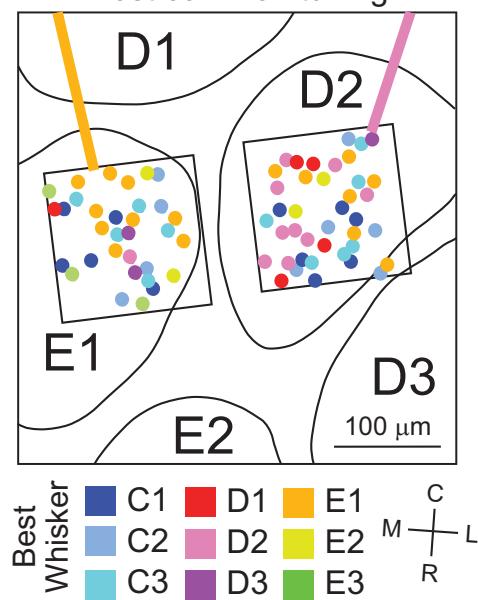

d

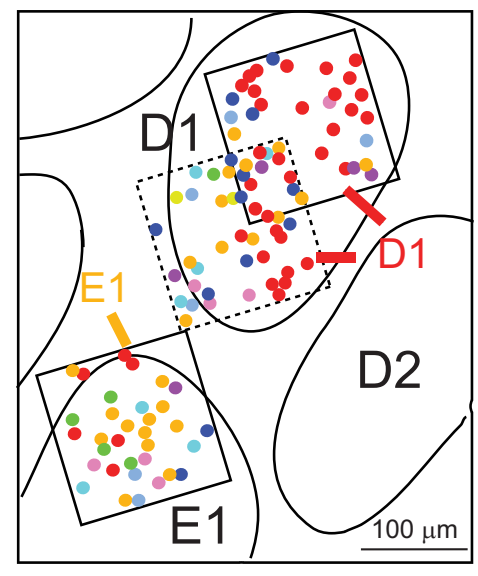

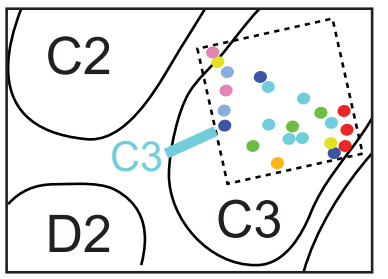

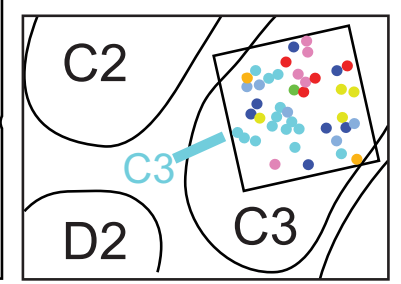

Figure 3. Anatomical localization of imaging fields. $\boldsymbol{a}$, Low-magnification two-photon image of OGB-1AM loaded cortex showing surface blood vessels. $\boldsymbol{b}$, The same blood vessel configuration in a flattened, CO-stained, histological section. Boxes show locations of two imaging fields, with FBW ofE1 and D2, respectively. c, Best whisker tuning for each neuron in these fields, superimposed on L4 barrel outlines from CO-stained sections. The most common BW (the FBW) for each field is shown in colored text, and matches the anatomical localization of each field. $\boldsymbol{d}$, Same for five additional imaging fields in two mice. Left, Dashed field was located $\sim 20 \mu \mathrm{m}$ in z above solid field. Right, Two imaging fields $40 \mu \mathrm{m}$ apart in $z$, but directly aligned in $x-y$. 0 ne additional imaging field is omitted for space reasons.

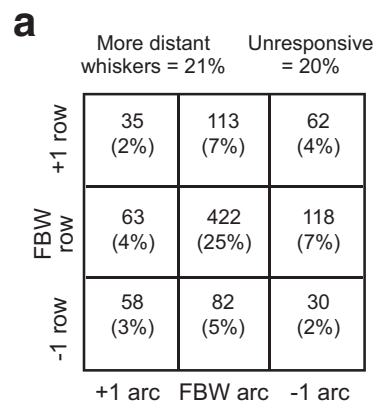

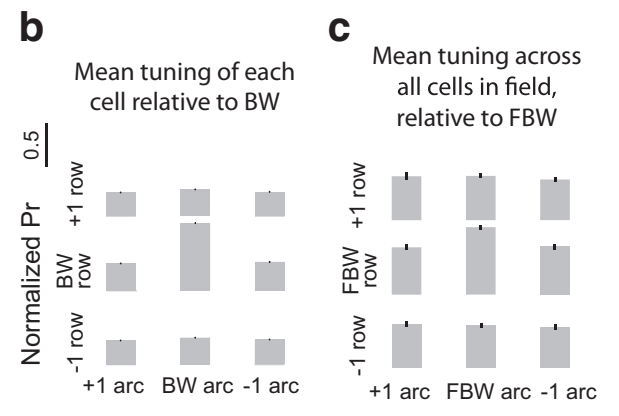

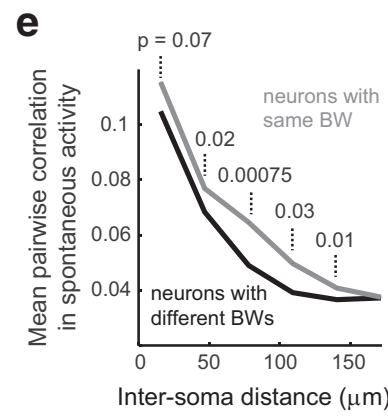

Figure 4. Quantification of tuning heterogeneity. $\boldsymbol{a}$, Number of neurons tuned to different whiskers, across all fields. $\boldsymbol{b}$, Average single-cell tuning curve. Responses were centered around the individual cells' BW and responses normalized to $\mathrm{Pr}_{\mathrm{BW}}$. Bars show SEM. $\boldsymbol{c}$, Average single-field tuning curve (calculated across all cells in a field). Responses were centered around the FBW. $\boldsymbol{d}$, WSI for individual cells versus fields, showing that individual neurons are more narrowly tuned than fields. $\boldsymbol{e}$, Mean pairwise correlation of calcium events during spontaneous periods, for neurons that share the same BW versus neurons with different BWs. Increased spontaneous correlations were observed among cotuned neurons.

of single spikes, the true size of the single-trial spiking ensemble for the FBW may be $\sim 14 \%$ of L 2 neurons in its home column and $\sim 10 \%$ of neurons in each adjacent and diagonal column.

We used these data, and our measured distribution of $\mathrm{Pr}$ across neurons, to simulate the distribution of spiking neurons across multiple S1 columns in response to a single rostral deflection of the center-column whisker under our anesthesia conditions (Fig. 6b,c). We simulated nine adjacent columns of 100 neurons each. For each neuron, whisker tuning and Pr were randomly sampled from our pooled, measured data, and were used to generate a Poisson spike train in response to repeated trials of whisker deflection. This approach assumes that the average imaging field represents a column. We ignored variations in Pr with distance from column center (Kerr et al., 2007; Sato et al., 2007), and mapping of direction tuning (Andermann and Moore, 2006; Kremer et al., 2011). The simulation shows quantitatively the sparsity of L2 spiking to single-whisker stimuli, and demonstrates that tuning and spiking ensembles are spread across multiple cortical columns, with spiking ensembles being much less focused than the tuning ensemble. Eighty-two percent of whisker-evoked spikes occurred outside the central column. The single-trial spiking ensemble was only partly overlapping with the tuning ensemble, because many spikes were evoked in neurons with peak tuning to nearby whiskers. Overall, $65 \%$ of spiking occurred in the $30 \%$ most responsive neurons.

\section{Factors that distinguish high- from low-pr neurons}

Within the skewed Pr distribution, high- and low-Pr neurons could represent different cell types, different pyramidal cell subcircuits, or could simply reflect different sensory tuning among otherwise identical pyramidal cells (Barth and Poulet, 2012). We examined the relative contribution of each of these factors. We first tested whether Pr varied with tuning to different whiskers (analyzing only whiskerresponsive neurons). Within an imaging field, neurons with high $\operatorname{Pr}_{\mathrm{BW}}$ were only slightly more likely to be tuned to the FBW than neurons with low $\operatorname{Pr}_{\mathrm{BW}}$ (Fig. 5b, black line). High- and low- $P \mathrm{r}_{\mathrm{BW}}$ neurons did not differ in tuning width (WSI; Fig. 5c). To avoid measurement bias, WSI was calculated here using equal numbers of calcium events in high- and low- $P$ r cells. Consistent with this, $\operatorname{Pr}_{\mathrm{BW}}$ did not differ substantially between cells with the highest- and lowest-quartile WSIs (Fig. $5 d$ ). Thus, $\operatorname{Pr}_{\mathrm{BW}}$ was not strongly predicted by best whisker identity or tuning width.

We next tested whether high-Pr neurons represent inherently more active neurons, independent of stimulus choice (Gentet et 
al., 2010; Yassin et al., 2010; Barth and Poulet, 2012; Margolis et al., 2012). To test this idea, we compared $\operatorname{Pr}_{\mathrm{BW}}$ with spontaneous activity rates, which are not determined by stimulus choice. Spontaneous rates were stable across hours of imaging (2677 cells in 51 animals, $t$ test early versus late mean spontaneous rate, $p=$ 0.83 ), and did not change after epochs of whisker stimulation (1620 cells in 29 animals; $t$ test prestimulus vs poststimulus spontaneous rates, $p=0.98)$. We observed a broad range of spontaneous activity rates (Fig. 7a; de Kock et al., 2007; Kerr et al., 2007; O’Connor et al., 2010b) and found that spontaneous rate was strongly correlated with $\operatorname{Pr}_{\mathrm{BW}}$ (Fig. $7 b ; R^{2}$ $=0.32, p<1 \mathrm{e}-16)$. Examples of this correlation can be seen in raw $\Delta F / F$ traces in Figure 1e. We used the rank-order of $\mathrm{Pr}$ and spontaneous rates within each field to compare across animals with variable anesthesia levels. We only included fields where a large number of cells were recorded, to fairly sample from a broad distribution of cells. Cells with high $P \mathrm{r}_{\mathrm{BW}}$ also had high $P r$ to non-BW whiskers (Fig. $\left.7 c ; R^{2}=0.69, p<1 \mathrm{e}-14\right)$, consistent with a generally more responsive subset of neurons. These correlations do not reflect contamination of evoked Pr by spontaneous activity, because $\operatorname{Pr}$ was calculated as net $P r$ above spontaneous event rate. $P r_{B W}$ was not correlated to SNR, ruling out an artifact of OGB loading or imaging noise (Fig. $7 d ; R^{2}=0.02, p=1.5 \mathrm{e}-13$ ). On the population level, cells with the highest quartile of spontaneous rate dominated the population of high $\operatorname{Pr}_{\mathrm{BW}}$ cells (Fig. 7e), as observed in A1 (Sakata and Harris, 2009). The correlation between spontaneous rate and $\operatorname{Pr}_{\mathrm{BW}}$ was also significant for raw $\Delta F / F$ and for unthresholded, deconvolved data (data not shown). Thus, a spectrum of inherent responsiveness exists across L2 neurons, independent of stimulus choice.

To rule out the possibility that the correlation between spontaneous rate and whisker-evoked responsiveness was an artifact of relatively low spike detection with calcium imaging, we performed an independent set of experiments using tetrode recordings to measure single-unit spiking in L2/3 under identical anesthetic conditions ( $n=8$ mice). Single units were isolated with standard methods. To exclude fast-spiking interneurons, we only analyzed units with spike width $>0.6 \mathrm{~ms}$ (Gabernet et al., 2005). A strong correlation was observed between spontaneous firing rate and principal whisker-evoked spike rate, calculated as net firing above spontaneous rate (Fig. $7 f ; n=43$ single units, $R^{2}=0.60, p=$ 1.2e-09). This confirms the correlation observed with imaging.

\section{High Pr cells include both pyramidal cells and interneurons}

High $\operatorname{Pr}_{\mathrm{BW}}$ cells may be interneurons, which have substantially higher spontaneous firing rates than pyramidal cells in $\mathrm{L} 2 / 3$ (Gentet et al., 2010). High Pr neurons in our dataset are unlikely to be FS interneurons, because the high firing rate of these cells obscures discrete spike-evoked calcium events that would be detectable by the deconvolution method. To test what fraction of high $\operatorname{Pr}_{\mathrm{BW}}$ b

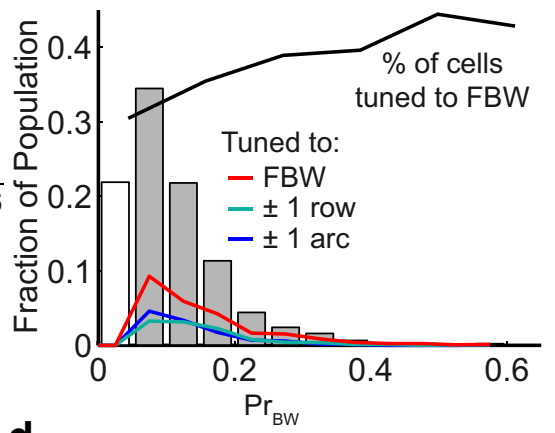

d

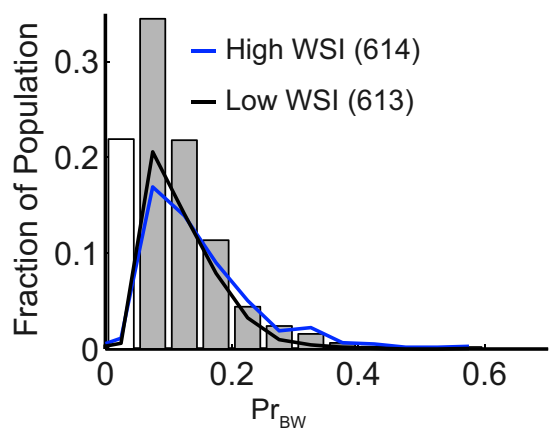

Figure 5. Effect of whisker tuning on neural responsiveness. $\boldsymbol{a}$, $\operatorname{Pr}$ distribution across all imaged cells. Black curve, $\operatorname{Pr}_{\mathrm{FBW}}$ (not cont corve, $\operatorname{Pr}_{\mathrm{BW}}$ (not corrected for spontaneous firing). Histogram bars, $\operatorname{Pr}_{\mathrm{BW}}$ corrected for 列 (narrowly tuned) and lowest-quartile WSI (broadly tuned) neurons.

neurons are interneurons, we imaged whisker-evoked responses in GAD67-GFP heterozygous mice, which label all interneurons with GFP (Tamamaki et al., 2003; Fig. $8 a-g$ ). Only three whiskers were stimulated in these experiments. Interneurons showed significantly higher spontaneous event rates than GFP-negative neurons (putative pyramidal cells; $p=0.002$, Wilcoxon rank sum test), and showed a nonsignificant trend for higher $\operatorname{Pr}_{\mathrm{BW}}(p=0.09$, Wilcoxon rank sum test). However, the high $\operatorname{Pr}_{\mathrm{BW}}$ population included both putative pyramidal cells and interneurons (Fig. $8 e-g$ ). We confirmed the skewness of the Pr distribution in pyramidal cells by expressing GCaMP6f in pyramidal cells using a dual virus strategy (AAV9.CaMKII0.4.Cre.SV40;

AAV9.Syn.Flex.GCaMP6f.WPRE.SV40; $n=3$ mice; (Fig. $8 H-J$ ). Pyramidal cells $(n=312)$ showed a skewed distribution of $\operatorname{Pr}_{\mathrm{BW}}$, including a tail of high-responsive neurons, and spontaneous activity and $\mathrm{Pr}_{\mathrm{BW}}$ were highly correlated within the pyramidal cell population. Absolute Pr values are not readily comparable to OGB-1 experiments, because we did not calibrate single-spike detection efficiency for GCaMP6 imaging.

\section{Tuning and responsiveness differ between M1- and S2-projecting neurons}

Finally, we tested whether high- and low-Pr cells represented pyramidal cell subclasses projecting to different downstream targets of S1. Different output streams from primary sensory cortex can be specialized to represent different sensory features and to have different spike rates (Movshon and Newsome, 1996; Sato and Svoboda, 2010; Jarosiewicz et al., 2012; J. L. Chen et al., 2013; 
a

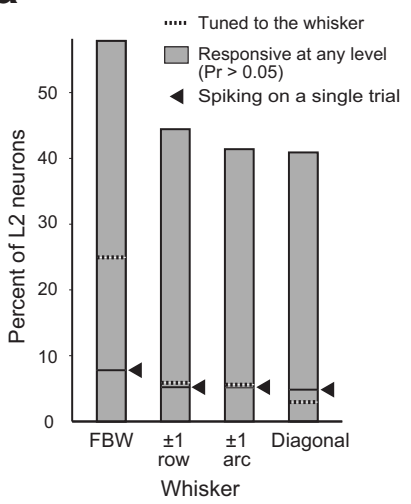

b

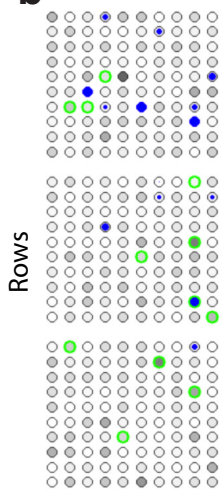

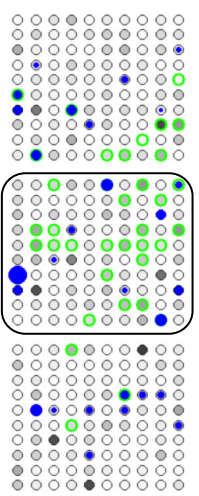

Arcs
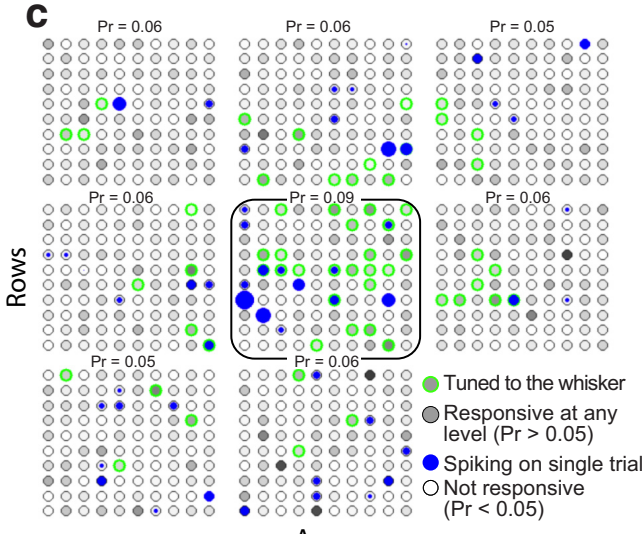

Arcs

Figure 6. Point representation of one whisker in L2 of S1. a, Number of cells in each imaging field that were minimally responsive to one given whisker ( $P r \geq 0.05)$, tuned to that whisker, or that spiked to that whisker on a single average trial. $\boldsymbol{b}, \boldsymbol{c}$, Summary of the point representation of a single whisker deflection in L2, from a simulation of cortical activity based on measured whisker tuning and Pr. Eight neighboring cortical columns are shown, with 100 neurons each. A single rostral deflection of the whisker corresponding to the central barrel column was simulated. Each cell is shaded gray to indicate $P r$ to the center-column whisker (white is low Pr, black is highest $P r$ ). Cells outlined in green are those tuned to the center-column whisker. $\boldsymbol{b}, \boldsymbol{c}$, Two representative trials of whisker deflection. Each blue circle represents a spiking response (1 or more spikes) above spontaneous firing, with the size of circle corresponding to the cell's Pr. For each column, mean Pr to deflection of the central whisker is shown. The spiking ensemble is sparse and distributed broadly across columns, more broadly than the tuning ensemble.

a
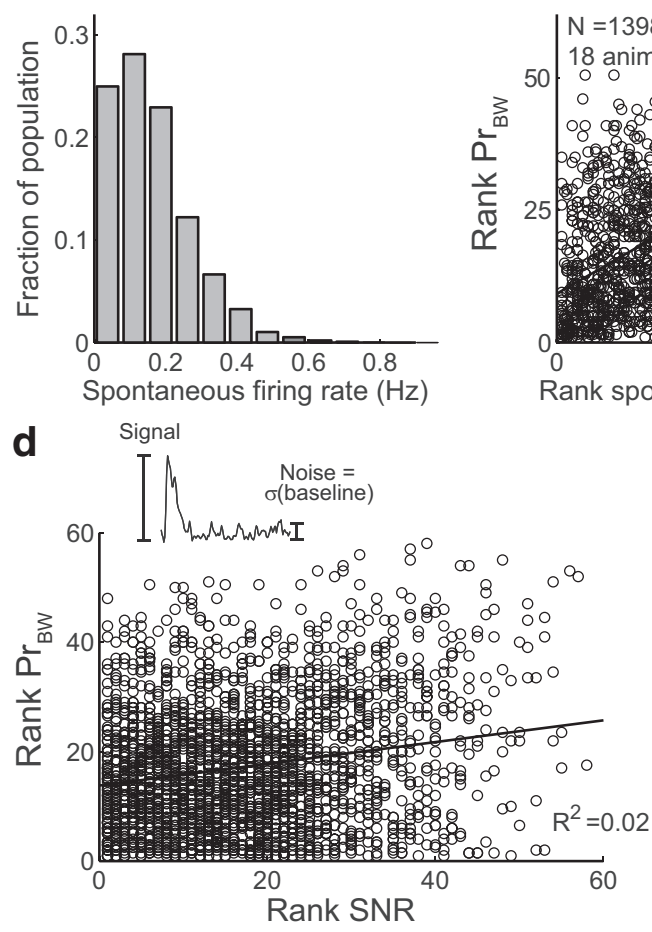

b

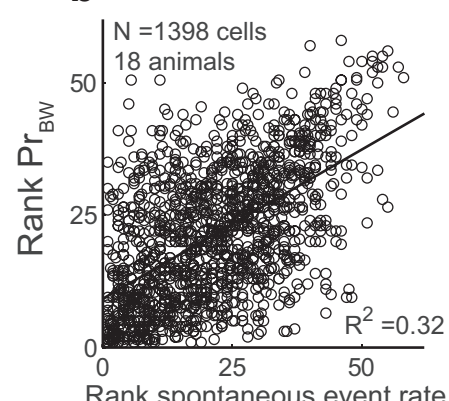

e

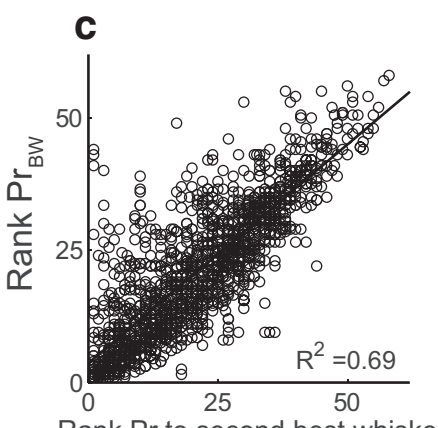

Rank Pr to second best whisker

f

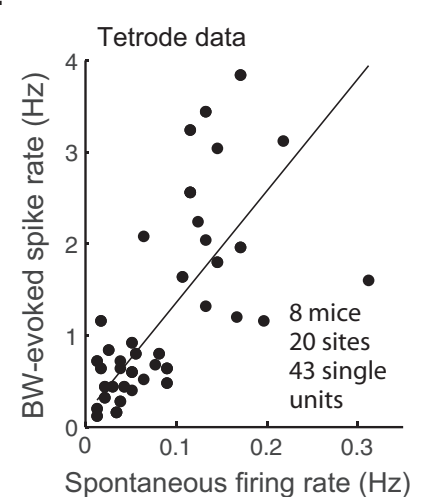

Figure 7. Whisker-evoked responsiveness correlates with spontaneous activity. $\boldsymbol{a}$, Histogram of spontaneous firing rates. $\boldsymbol{b}$, Correlation between $\operatorname{Pr}_{\mathrm{BW}}$ and spontaneous firing rate, calculated by rank within the imaging field for each neuron. Only data from fields with $>30$ cells are included to ensure adequate sampling of response properties in each field. $\boldsymbol{c}$, Same as $\boldsymbol{b}$ but for $\operatorname{Pr}$ to each neurons second-best whisker. $\boldsymbol{d}, \mathrm{SNR}$ and $\mathrm{Pr}_{\mathrm{BW}}$ are not correlated. Inset, SNR calculation. $\boldsymbol{e}$, Effect of spontaneous firing rate on $\operatorname{Pr}_{\mathrm{BW}}$. Histogram bars show entire population, reproduced from Figure $5 A$. Solid and dashed curves, neurons with lowest and highest quartile of spontaneous activity. $f$, Correlation between best whisker-evoked spike rate and spontaneous spike rate, for single $L 2 / 3$ units recorded with tetrodes.

Glickfeld et al., 2013; Yamashita et al., 2013). Output targets of L2 of $\mathrm{S} 1$ include primary motor cortex (M1) and S2, with only modest overlap (1-10\%) between these populations (Sato and Svoboda, 2010; J. L. Chen et al., 2013; Yamashita et al., 2013). We compared whisker tuning and sparse coding between these populations by labeling M1-projecting (M1p) neurons or S2projecting (S2p) neurons in separate experiments by injecting the retrograde tracer CTB-AlexaFluor 594 into either M1 or S2 (Fig.
9). After allowing time for CTB transport, we imaged in S1 and recorded activity from M1p or S2p neurons and unlabeled neurons. The latter represent both neurons that do not project to M1/S2 and an unknown fraction of unlabeled M1p/S2p neurons. M1p, S2p, and unlabeled neurons did not differ in spontaneous event rate. M1p neurons (Fig. $9 a$ ) had similar $P \mathrm{r}_{\mathrm{BW}}$ to unlabeled cells (Fig. $9 b ; p=0.29$, Wilcoxon rank sum test), but were more broadly tuned (Fig. $9 c ; p=2.9 \mathrm{e}-4$, Wilcoxon rank sum test), as 
a GAD67-GFP mice b

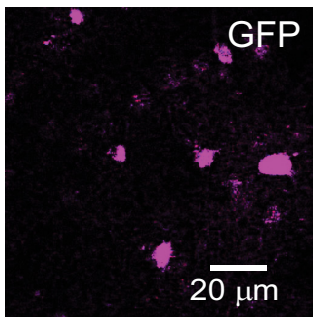

e

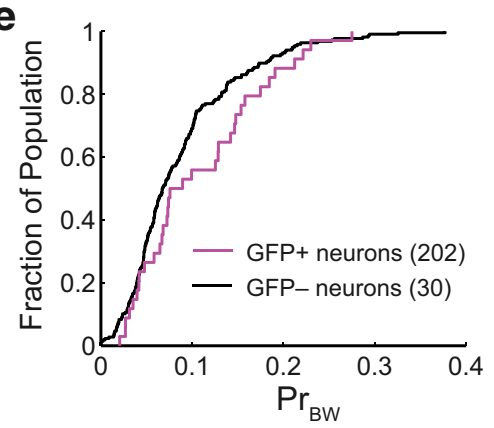

b

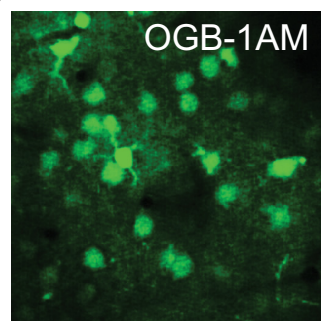

f

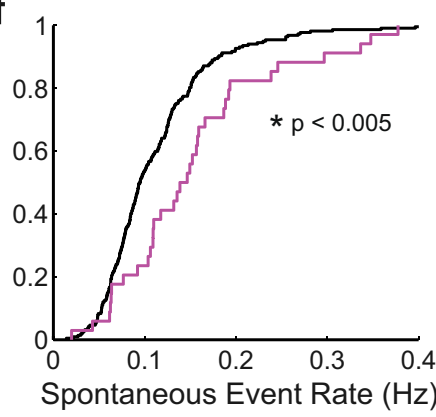

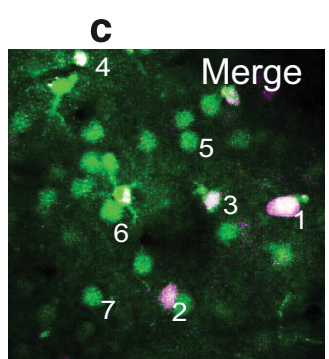

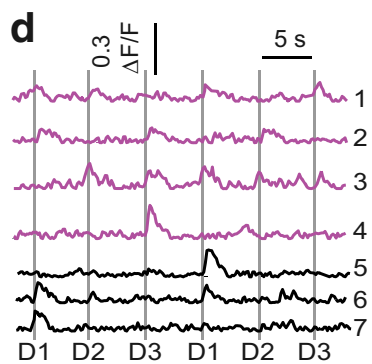

g

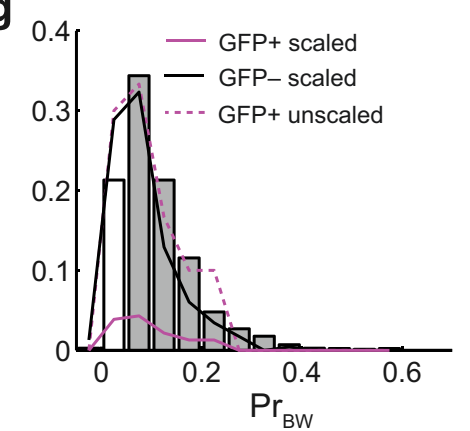

h

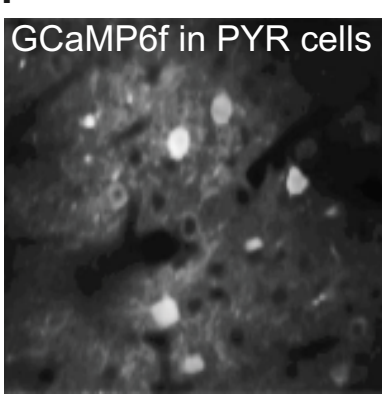

i

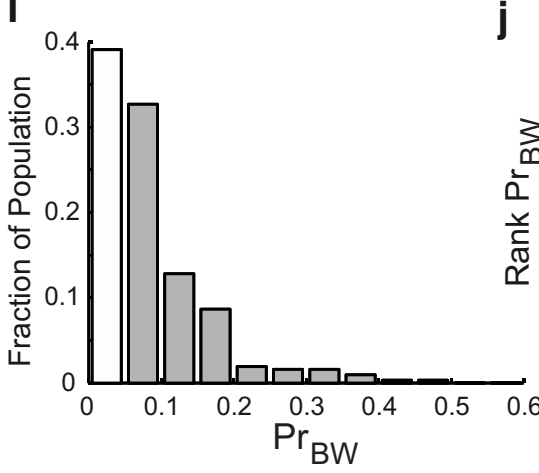

j

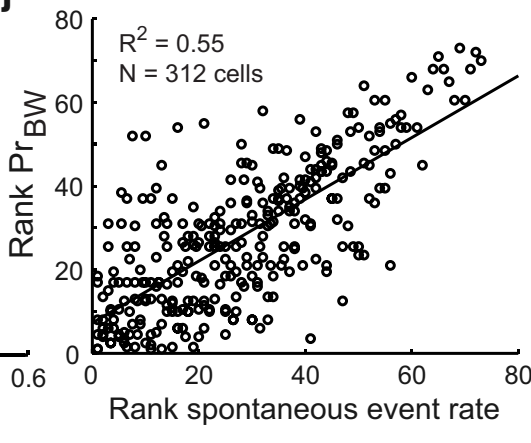

Figure 8. Responsiveness of interneurons versus pyramidal cells. $\boldsymbol{a}-\boldsymbol{g}$, Responsiveness in GAD67-GFP mice. $\boldsymbol{a}$, Example imaging field showing GFP-labeled interneurons ( $\boldsymbol{a}$; imaged at $920 \mathrm{~nm}$ ), $0 G B-1$ dye loading $\left(\boldsymbol{b}\right.$; imaged at $800 \mathrm{~nm}$ ), and (c) the overlay. $\boldsymbol{d}, \Delta F / F$ traces for four neurons indicated in $\boldsymbol{c}$. Magenta traces are interneurons. $\boldsymbol{e}, \boldsymbol{f}$, Cumulative distributions of $\mathrm{Pr}_{\mathrm{BW}}$ and spontaneous firing rate for interneurons and putative pyramidal cells. $\boldsymbol{g}$, Distribution of $\operatorname{Pr}_{\mathrm{BW}}$ for interneurons and putative pyramidal cells (curves), overlaid on $\operatorname{Pr}_{\mathrm{BW}}$ for all neurons (bars, replotted from Fig. 6a). $\boldsymbol{h}-\boldsymbol{j}$, Responsiveness of pyramidal cells measured with GCaMP6f expressed selectively in pyramidal cells using a CaMKII promoter and dual virus strategy (see text). $\boldsymbol{h}$, Example imaging field. $\boldsymbol{i}$, Skewed distribution of $\mathrm{Pr}_{\mathrm{BW}}$ in $\mathrm{L} 2$ pyramidal cells. $j, \mathrm{Pr}_{\mathrm{BW}}$ was strongly correlated with spontaneous event rate in pyramidal cells.

reported previously (Sato and Svoboda, 2010). M1p neurons were equally likely to be tuned to the FBW as unlabeled neurons $(p=0.3$, binomial test; Fig. 9d).

In contrast, S2p neurons (Fig. $9 e$ ) had significantly higher $\operatorname{Pr}_{\mathrm{BW}}$ than unlabeled neurons (Fig. $9 f ; p=9.9 \mathrm{e}-4$, Wilcoxon rank sum test) and were more narrowly tuned (Fig. $9 \times g ; p=0.02$, Wilcoxon rank sum test). S2p neurons were also more likely to be tuned to the FBW than unlabeled or M1p neurons (Fig. $9 d ; p=$ 0.02 , binomial test). Thus, M1p and S2p neurons occupied modestly different places within the $\operatorname{Pr}_{\mathrm{BW}}$ distribution (Fig. 9h). The differences between S2p and unlabeled neurons were not evident if analysis was restricted to just two whiskers, as in a prior study (Sato and Svoboda, 2010; data not shown). Thus, S2p neurons encoded deflection of the columnar whisker more strongly and with more spatial precision than M1p neurons.

These findings suggest that S2p neurons may encode FBW deflections more accurately than other neurons. To test this, we calculated the mutual information between calcium events and the identity of the deflected whisker. S2p neurons had significantly higher mutual information about the occurrence of FBW deflections than unlabeled neurons in the same experiments, or than M1p neurons ( $p<0.01, t$ test; Fig. $9 i)$.

\section{Discussion}

$\mathrm{Ca}^{2+}$ imaging is well suited to measure sensory tuning of $\mathrm{L} 2 / 3$ pyramidal cells (Stosiek et al., 2003; Kerr et al., 2005, 2007; Ohki et al., 2005). Prior $\mathrm{Ca}^{2+}$ imaging studies revealed sparse, lowprobability sensory responses in L2/3 of S1, a gradient of whiskerevoked response probability from column centers to edges, and salt-and-pepper organization for whisker direction tuning (Kerr et al., 2007; O'Connor et al., 2010b; Kremer et al., 2011; Gdalyahu et al., 2012; Margolis et al., 2012). Prior studies also showed that two-whisker dominance (the relative response to two adjacent whiskers) has high local scatter superimposed on a slow progression across columns, suggesting distributed somatotopy (Sato et al., 2007; Sato and Svoboda, 2010). We measured full whisker receptive fields and true somatotopy by imaging responses to 9-15 whiskers. We found surprising heterogeneity of whisker tuning within single columns, with only $25 \%$ of neurons in each imaging field tuned to the field best whisker, $34 \%$ tuned to adjacent and diagonal whiskers, and 19\% tuned to distant, nonadjacent whiskers (Fig. 4). These were interspersed locally in a salt-and-pepper arrangement (Figs. 2,3). Despite local tuning diversity, the modal best whisker within each field matched anatomical column identity, 
a
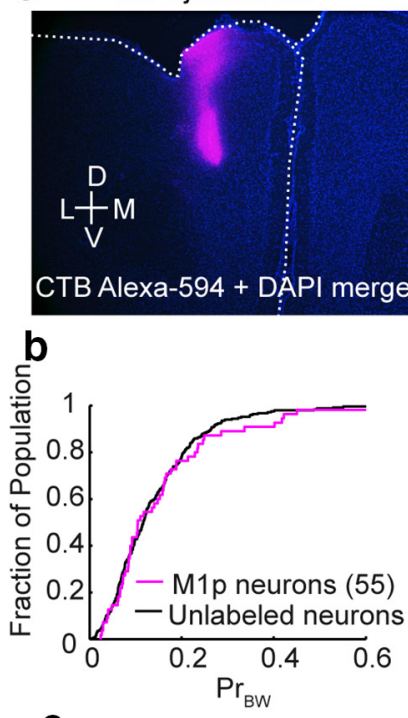

e

S2 injection site
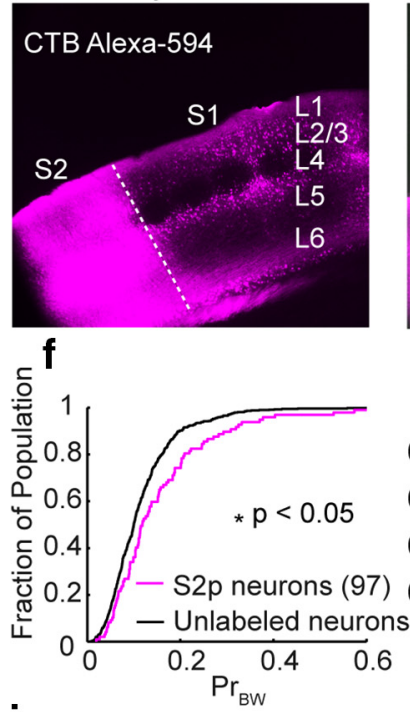

i

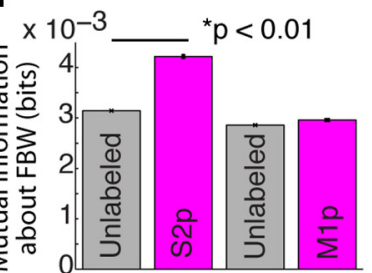

Figure 9. S2p and M1p pyramidal cells differ in responsiveness and tuning. $\boldsymbol{a}$, (TB-AlexaFluor 594 injection site in M1 (left) that labeled M1p cells in S1 (magenta cells in middle and right; visible among green OGB-1 labeled neurons). Right, An example imaging field in $\mathrm{S1.} \boldsymbol{b}, \boldsymbol{c}$, Cumulative distributions of $\mathrm{Pr}_{\mathrm{BW}}$ and WSI for M1p and unlabeled neurons. $\boldsymbol{d}$, Fraction of each population that were tuned to the FBW.e, (TB-AlexaFluor 594 injection site in S2, and S2p cells (magenta) in S1.f, $\boldsymbol{g}$, Cumulative distributions of $\operatorname{Pr}_{B W}$ and WSI for S2p unlabeled neurons. $\boldsymbol{h}, \operatorname{Pr}_{B W}$ distribution for M1p and S2p neurons overlaid on the distribution for all neurons. Bars are reproduced from Figure $5 a$. $i$, Mutual information between calcium events and FBW deflection, calculated across trials, for different populations of $L 2$ neurons. Unlabeled neurons from S2p cases and M1p cases are shown separately.
From these results, we can calculate the spatial spread of neurons tuned for one whisker (the tuning ensemble). Assuming that an imaging field represents a column, $32 \%$ of neurons in the tuning ensemble are located in the anatomically corresponding column, $29 \%$ in the four immediately adjacent row and arc columns, $14 \%$ in the four adjacent diagonal columns, and $24 \%$ in more distant columns. Thus, the tuning ensemble for one whisker is scattered across multiple columns, with $\sim 4 \times$ greater density in the home column than any one adjacent column (Fig. 6).

\section{Structure of the sparse code in L2}

The cortical point representation in S1 can be defined as the number and spatial distribution of neurons that spike to a single whisker deflection, and is a product of the spatial spread of the tuning ensemble, receptive field width for individual neurons, and whisker-evoked response probability for each neuron. Rodent sensory cortex exhibits sparse coding based both on narrow stimulus selectivity and low $P r$ (de Kock et al., 2007; Hromádka et al., 2008; Jadhav et al., 2009; Poo and Isaacson, 2009; Stettler and Axel, 2009). In L2/3 of $S 1$, average $P r$ is low for single-whisker stimuli, and a skewed distribution of $P r$ exists across L2/3 neurons, with a small population of high-Pr neurons generating most whisker-evoked spikes (Kerr et al., 2007; de Kock et al., 2007; de Kock and Sakmann, 2009; O'Connor et al., 2010b; Crochet et al., 2011; Margolis et al., 2012; Sachidhanandam et al., 2013). Pr is determined, in part, by excitation-inhibition ratio, which varies across neurons (Crochet and Petersen, 2006). However, it remains unclear whether high- and low- $P r$ neurons are different cell classes (e.g., interneurons vs pyramidal cells; Gentet et al., 2010), different pyramidal cell subclasses (Yassin et al., 2010), or a product of differential sensory tuning among otherwise equivalent pyramidal cells (Barth and Poulet, 2012). We tested the relative contribution of these factors in determining $P r$, and measured how low, skewed Pr impacts the cortical point representation.

We confirmed a low and skewed distribution of $P r$ to deflection of the columnar consistent with orderly mean topography in the whisker map (Simons, 1978; Armstrong-James and Fox, 1987). Thus, our results confirm salt-and-pepper micro-organization for somatotopy in $\mathrm{L} 2 / 3$ of $\mathrm{S} 1$, similar to retinotopy and orientation tuning in V1 and tonotopy in A1 (Ohki et al., 2005; Kerr et al., 2007; Sato et al., 2007; Bandyopadhyay et al., 2010; Rothschild et al., 2010; Bonin et al., 2011). whisker (de Kock et al., 2007; Kerr et al., 2007; O'Connor et al., 2010b; Crochet et al., 2011; Margolis et al., 2012; Sachidhanandam et al., 2013). Pr to each neuron's individually determined best whisker $\left(\mathrm{Pr}_{\mathrm{BW}}\right)$ was also low (mean: 0.12$)$ and skewed (Fig. $5 a) . P \mathrm{r}_{\mathrm{BW}}$ correlated only weakly with sensory tuning (Fig. 5), but strongly with spontaneous firing rate (Fig. 7), as in A1 and other areas (Sakata and Harris, 2009; Buzsáki and Mizuseki, 2014). This 
indicates that a major component of responsiveness is independent of stimulus choice. More active cells included both interneurons, as expected (Gentet et al., 2010), and also many pyramidal cells (Fig. 8). Among pyramidal cells, S2p cells were more responsive than M1p cells (Fig. 9). These results are consistent with the existence of a more active subclass of pyramidal cells that receive greater excitation from the local network (Yassin et al., 2010; Benedetti et al., 2013). High- $P \mathrm{r}_{\mathrm{BW}}$ neurons also spike more to L4 microstimulation, but are not intrinsically more excitable (Elstrott et al., 2014), indicating specializations in local cortical circuits. An important caveat is that the absolute Pr values reported here might be underestimated due to incomplete singlespike detection. However, the findings of salt-and-pepper somatotopy and cell type- and pathway-specific response properties are based on relative $P r$, not absolute $P r$, and should be robust to incomplete spike detection.

\section{The point representation of a whisker in L2}

We performed a simple simulation based on whisker receptive field and Pr data to determine the spatial organization of the single-trial spiking ensemble for a whisker (the set of neurons that spike to a single whisker deflection) and the minimally responsive ensemble (the complete set of neurons with nonzero $\mathrm{Pr}$ to that whisker, sampled over many trials). Both spiking ensembles include many neurons outside the tuning ensemble, because S1 neurons respond to multiple nonbest whiskers. Because mean $\operatorname{Pr}$ is low, the single-trial spiking ensemble is a small, shifting subset of the minimally responsive ensemble. Both spiking ensembles are broadly spread across columns: fully $82 \%$ of spiking neurons are located outside the home column, and the ratio of whisker-evoked spikes in one surround column versus the home column is $\sim 0.70$. This agrees well with a prior study $(0.77$; Kerr et al., 2007). Thus, the point representation in L2 is spread much more broadly than the tuning ensemble, and includes a substantial number of neurons in a nine-column region. This distributed representation is fundamentally distinct from topographically focused activation in L4 (Petersen and Diamond, 2000).

This distributed representation may reflect dynamic spread of cortical activity during one to two imaging frames (Ferezou et al., 2007), and is similar to a functional whisker representation measured by intrinsic signal imaging (Polley et al., 1999). Although a spatially distributed representation contrasts with the standard idea of S1 columnar precision, it is consistent with some singleunit recording studies showing that $4-10 \%$ of L $2 / 3$ single units spike more to one arbitrarily chosen neighboring-arc or -row whisker than to the home-column whisker (Fox, 1992; Glazewski and Fox, 1996; Glazewski et al., 1999, 2000).

\section{Specializations of S2 and M1 output pathways}

Cortical pyramidal neurons projecting to distinct long-range target areas can exhibit specialized sensory tuning and firing patterns (Movshon and Newsome, 1996; Sato and Svoboda, 2010; Jarosiewicz et al., 2012; Petreanu et al., 2012; J. L. Chen et al., 2013; Glickfeld et al., 2013; Yamashita et al., 2013). In S1, M1p and S2p pyramidal cells differ in sensory tuning, intrinsic biophysics, recruitment during different behavioral tasks, and dynamics of whisking- and contact-related spikes (Sato and Svoboda, 2010; J. L. Chen et al., 2013; Yamashita et al., 2013). By receptive field mapping across many whiskers, we found that S2p neurons were more narrowly tuned than other neurons, were more likely to be tuned to the column-related whisker, and had higher $\operatorname{Pr}_{\mathrm{BW}}$. This agrees with the finding that $\mathrm{S} 2 \mathrm{p}$ neurons exhibit stronger, more sustained spiking during active touch than
M1p neurons, and are more synaptically excitable (Yamashita et al., 2013). In contrast, M1p neurons were more broadly tuned to multiple whiskers (Fig. 9), as in a prior study (Sato and Svoboda, 2010). M1p and S2p neuronal identity modestly predicted a neuron's position on the $P_{\mathrm{BW}}$ distribution (Fig. 9). Because of higher $\mathrm{Pr}$, narrower tuning, and greater likelihood to be tuned to the columnar whisker, each S2p neuron carried more information about columnar whisker deflections (Fig. 9). Thus, S2p and M1p subpopulations sample different whisker information, coded with different spike probability, from the distributed point representation in $\mathrm{L} 2$.

\section{Summary}

These data show that single whisker deflection elicits sparse spikes in small, shifting ensembles of L2 neurons spanning many cortical columns (Kerr et al., 2007). This sparse, divergent code is a substantial transformation from L4, where $P r$ is higher and more neurons are tuned for the column-appropriate whisker (Armstrong-James and Fox, 1987; de Kock et al., 2007; Le Cam et al., 2011). The sparse code in L2 is highly structured, with a small tail of inherently more responsive pyramidal cells and differences in responsiveness and sensory tuning between S2 and M1 output streams. Somewhat stronger spiking is expected in awake animals (Niell and Stryker, 2010). Low-responsive neurons contribute to the spatial spread of the point representation into surrounding columns. These neurons may also represent a reserve pool to be recruited during plasticity, or in behavioral tasks by association with reward (J. L. Chen et al., 2013; Clancy et al., 2014).

\section{Notes}

Supplemental material for this article is available at http://mcb.berkeley. edu/labs/feldman/resources.html. This is a movie showing the full simulation described in Figure 6. Point representation of a single whisker deflection in L2 of S1, shown by simulation of spiking across nine columns in response to deflection of the whisker corresponding to the central column. This material has not been peer reviewed.

\section{References}

Andermann ML, Moore CI (2006) A somatotopic map of vibrissa motion direction within a barrel column. Nat Neurosci 9:543-551. CrossRef Medline

Armstrong-James M, Fox K (1987) Spatiotemporal convergence and divergence in the rat S1 "barrel" cortex. J Comp Neurol 263:265-281. CrossRef Medline

Bandyopadhyay S, Shamma SA, Kanold PO (2010) Dichotomy of functional organization in the mouse auditory cortex. Nat Neurosci 13:361368. CrossRef Medline

Barth AL, Poulet JF (2012) Experimental evidence for sparse firing in the neocortex. Trends Neurosci 35:345-355. CrossRef Medline

Benedetti BL, Takashima Y, Wen JA, Urban-Ciecko J, Barth AL (2013) Differential wiring of layer $2 / 3$ neurons drives sparse and reliable firing during neocortical development. Cereb Cortex 23:2690-2699. CrossRef Medline

Bonin V, Histed MH, Yurgenson S, Reid RC (2011) Local diversity and fine-scale organization of receptive fields in mouse visual cortex. J Neurosci 31:18506-18521. CrossRef Medline

Brecht M, Roth A, Sakmann B (2003) Dynamic receptive fields of reconstructed pyramidal cells in layers 3 and 2 of rat somatosensory barrel cortex. J Physiol 553:243-265. CrossRef Medline

Bureau I, Bureau I, von Saint Paul F, Saint Paul von F, Svoboda K, Svoboda K (2006) Interdigitated paralemniscal and lemniscal pathways in the mouse barrel cortex. PLoS Biol 4:e382. CrossRef Medline

Buzsáki G, Mizuseki K, (2014) The log-dynamic brain: how skewed distributions affect network operations. Nat Rev Neurosci 15:264-278. CrossRef Medline

Chen JL, Carta S, Soldado-Magraner J, Schneider BL, Helmchen F (2013) Behaviour-dependent recruitment of long-range projection neurons in somatosensory cortex. Nature 499:336-340. CrossRef Medline 
Chen TW, Wardill TJ, Sun Y, Pulver SR, Renninger SL, Baohan A, Schreiter ER, Kerr RA, Orger MB, Jayaraman V, Looger LL, Svoboda K, Kim DS (2013) Ultrasensitive fluorescent proteins for imaging neuronal activity. Nature 499:295-300. CrossRef Medline

Ch'ng YH, Reid RC (2010) Cellular imaging of visual cortex reveals the spatial and functional organization of spontaneous activity. Front Integr Neurosci 4:20. CrossRef Medline

Clancy KB, Koralek AC, Costa RM, Feldman DE, Carmena JM (2014) Volitional modulation of optically recorded calcium signals during neuroprosthetic learning. Nat Neurosci 17:807-809. CrossRef Medline

Crochet S, Petersen CC (2006) Correlating whisker behavior with membrane potential in barrel cortex of awake mice. Nat Neurosci 9:608-610. CrossRef Medline

Crochet S, Poulet JF, Kremer Y, Petersen CC (2011) Synaptic mechanisms underlying sparse coding of active touch. Neuron 69:1160-1175. CrossRef Medline

de Kock CP, Bruno RM, Spors H, Sakmann B (2007) Layer- and cell-typespecific suprathreshold stimulus representation in rat primary somatosensory cortex. J Physiol 581:139-154. CrossRef Medline

de Kock C, Sakmann B (2009) Spiking in primary somatosensory cortex duringnatural whisking in awake head-restrained ratsis cell-type specific. Proc Natl Acad Sci U S A 106:16446-16450. CrossRef Medline

Drew PJ, Feldman DE (2009) Intrinsic signal imaging of deprivationinduced contraction of whisker representations in rat somatosensory cortex. Cereb Cortex 19:331-348. CrossRef Medline

Elstrott J, Clancy KB, Jafri H, Akimenko I, Feldman DE (2014) Cellular mechanisms for response heterogeneity among L2/3 pyramidal cells in whisker somatosensory cortex. J Neurophysiol 112:233-248. CrossRef Medline

Ferezou I, Haiss F, Gentet LJ, Aronoff R, Weber B, Petersen CC (2007) Spatiotemporal dynamics of cortical sensorimotor integration in behaving mice. Neuron 56:907-923. CrossRef Medline

Fox K (1992) A critical period for experience-dependent synaptic plasticity in rat barrel cortex. J Neurosci 12:1826-1838. Medline

Gabernet L, Jadhav SP, Feldman DE, Carandini M, Scanziani M (2005) Somatosensory integration controlled by dynamic thalamocortical feedforward inhibition. Neuron 48:315-327. CrossRef Medline

Garaschuk O, Konnerth A (2010) In vivo two-photon calcium imaging using multicell bolus loading. Cold Spring Harb Protoc 2010:pdb.prot5482. CrossRef Medline

Gdalyahu A, Tring E, Polack PO, Gruver R, Golshani P, Fanselow MS, Silva AJ, Trachtenberg JT (2012) Associative fear learning enhances sparse network coding in primary sensory cortex. Neuron 75:121-132. CrossRef Medline

Gentet LJ, Avermann M, Matyas F, Staiger JF, Petersen CC (2010) Membrane potential dynamics of GABAergic neurons in the barrel cortex of behaving mice. Neuron 65:422-435. CrossRef Medline

Glazewski S, Fox K (1996) Time course of experience-dependent synaptic potentiation and depression in barrel cortex of adolescent rats. J Neurophysiol 75:1714-1729. Medline

Glazewski S, Barth AL, Wallace H, McKenna M, Silva A, Fox K (1999) Impaired experience-dependent plasticity in barrel cortex of mice lacking the alpha and delta isoforms of CREB. Cereb Cortex 9:249-256. CrossRef Medline

Glazewski S, Giese KP, Silva A, Fox K (2000) The role of alpha-CaMKII autophosphorylation in neocortical experience-dependent plasticity. Nat Neurosci 3:911-918. CrossRef Medline

Glickfeld LL, Andermann ML, Bonin V, Reid RC (2013) Cortico-cortical projections in mouse visual cortex are functionally target specific. Nat Neurosci 16:219-226. CrossRef Medline

Golshani P, Gonçalves JT, Khoshkhoo S, Mostany R, Smirnakis S, PorteraCailliau C (2009) Internally mediated developmental desynchronization of neocortical network activity. J Neurosci 29:10890-10899. CrossRef Medline

Grinvald A, Lieke E, Frostig RD, Gilbert CD, Wiesel TN (1986) Functional architecture of cortex revealed by optical imaging of intrinsic signals. Nature 324:361-364. CrossRef Medline

Harris KD, Mrsic-Flogel TD (2013) Cortical connectivity and sensory coding. Nature 503:51-58. CrossRef Medline

Hill DN, Mehta SB, Kleinfeld D (2011) Quality metrics to accompany spike sorting of extracellular signals. J Neurosci 31:8699-8705. CrossRef Medline

Hromádka T, Deweese MR, Zador AM (2008) Sparse representation of sounds in the unanesthetized auditory cortex. PLoS Biol 6:e16. CrossRef Medline

Isely G, Hillar C, Sommer FT (2011) Deciphering subsampled data: adaptive compressive sampling as a principle of brain communication. In: Advances in Neural Information Processing Systems, pp 910-918.

Jadhav SP, Wolfe J, Feldman DE (2009) Sparse temporal coding of elementary tactile features during active whisker sensation. Nat Neurosci 12:792800. CrossRef Medline

Jarosiewicz B, Schummers J, Malik WQ, Brown EN, Sur M (2012) Functional biases in visual cortex neurons with identified projections to higher cortical targets. Curr Biol 22:269-277. CrossRef Medline

Kerr JN, Greenberg D, Helmchen F (2005) Imaging input and output of neocortical networks in vivo. Proc Natl Acad Sci U S A 102:14063-14068. CrossRef Medline

Kerr JN, de Kock CP, Greenberg DS, Bruno RM, Sakmann B, Helmchen F (2007) Spatial organization of neuronal population responses in layer 2/3 of rat barrel cortex. J Neurosci 27:13316-13328. CrossRef Medline

Knott GW, Holtmaat A, Trachtenberg JT, Svoboda K, Welker E (2009) A protocol for preparing GFP-labeled neurons previously imaged in vivo and in slice preparations for light and electron microscopic analysis. Nat Protoc 4:1145-1156. CrossRef Medline

Ko H, Hofer SB, Pichler B, Buchanan KA, Sjöström PJ, Mrsic-Flogel TD (2011) Functional specificity of local synaptic connections in neocortical networks. Nature 473:87-91. CrossRef Medline

Komiyama T, Sato TR, O'Connor DH, Zhang YX, Huber D, Hooks BM, Gabitto M, Svoboda K (2010) Learning-related fine-scale specificity imaged in motor cortex circuits of behaving mice. Nature 464:1182-1186. CrossRef Medline

Kremer Y, Léger JF, Goodman D, Brette R, Bourdieu L (2011) Late emergence of the vibrissa direction selectivity map in the rat barrel cortex. J Neurosci 31:10689-10700. CrossRef Medline

Le Cam J, Estebanez L, Jacob V, Shulz DE (2011) Spatial structure of multiwhisker receptive fields in the barrel cortex is stimulus dependent. J Neurophysiol 106:986-998. CrossRef Medline

Lefort S, Tomm C, Floyd Sarria JC, Petersen CC (2009) The excitatory neuronal network of the $\mathrm{C} 2$ barrel column in mouse primary somatosensory cortex. Neuron 61:301-316. CrossRef Medline

Lübke J, Feldmeyer D (2007) Excitatory signal flow and connectivity in a cortical column: focus on barrel cortex. Brain Struct Funct 212:3-17. CrossRef Medline

Margolis DJ, Lütcke H, Schulz K, Haiss F, Weber B, Kügler S, Hasan MT, Helmchen F (2012) Reorganization of cortical population activity imaged throughout long-term sensory deprivation. Nat Neurosci 15:15391546. CrossRef Medline

Movshon JA, Newsome WT (1996) Visual response properties of striate cortical neurons projecting to area MT in macaque monkeys. J Neurosci 16:7733-7741. Medline

Niell CM, Stryker MP (2010) Modulation of visual responses by behavioral state in mouse visual cortex. Neuron 65:472-479. CrossRef Medline

O'Connor DH, Clack NG, Huber D, Komiyama T, Myers EW, Svoboda K (2010a) Vibrissa-based object localization in head-fixed mice. J Neurosci 30:1947-1967. CrossRef Medline

O'Connor DH, Peron SP, Huber D, Svoboda K (2010b) Neural activity in barrel cortex underlying vibrissa-based object localization in mice. Neuron 67:1048-1061. CrossRef Medline

Ohki K, Chung S, Ch'ng YH, Kara P, Reid RC (2005) Functional imaging with cellular resolution reveals precise micro-architecture in visual cortex. Nature 433:597-603. CrossRef Medline

Petersen RS, Diamond ME (2000) Spatial-temporal distribution of whisker-evoked activity in rat somatosensory cortex and the coding of stimulus location. J Neurosci 20:6135-6143. Medline

Petreanu L, Gutnisky DA, Huber D, Xu NL, O'Connor DH, Tian L, Looger L, Svoboda K (2012) Activity in motor-sensory projections reveals distributed coding in somatosensation. Nature 489:299-303. CrossRef Medline

Polley DB, Chen-Bee CH, Frostig RD (1999) Two directions of plasticity in the sensory-deprived adult cortex. Neuron 24:623-637. CrossRef Medline

Pologruto TA, Sabatini BL, Svoboda K (2003) ScanImage: flexible software for operating laser scanning microscopes. Biomed Eng Online 2:13. CrossRef Medline

Poo C, Isaacson JS (2009) Odor representations in olfactory cortex: "sparse" coding, global inhibition, and oscillations. Neuron 62:850-861. CrossRef Medline 
Rothschild G, Nelken I, Mizrahi A (2010) Functional organization and population dynamics in the mouse primary auditory cortex. Nat Neurosci 13:353-360. CrossRef Medline

Sachidhanandam S, Sreenivasan V, Kyriakatos A, Kremer Y, Petersen CC (2013) Membrane potential correlates of sensory perception in mouse barrel cortex. Nat Neurosci 16:1671-1677. CrossRef Medline

Sakata S, Harris KD (2009) Laminar structure of spontaneous and sensoryevoked population activity in auditory cortex. Neuron 64:404-418. CrossRef Medline

Sato TR, Svoboda K (2010) The functional properties of barrel cortex neurons projecting to the primary motor cortex. J Neurosci 30:4256-4260. CrossRef Medline

Sato TR, Gray NW, Mainen ZF, Svoboda K (2007) The functional microarchitecture of the mouse barrel cortex. PLoS Biol 5:e189. CrossRef Medline

Simons DJ (1978) Response properties of vibrissa units in rat SI somatosensory neocortex. J Neurophysiol 41:798-820. Medline

Simons DJ, Carvell GE (1989) Thalamocortical response transformation in the rat vibrissa/barrel system. J Neurophysiol 61:311-330. Medline

Stettler DD, Axel R (2009) Representations of odor in the piriform cortex. Neuron 63:854-864. CrossRef Medline

Stosiek C, Garaschuk O, Holthoff K, Konnerth A (2003) In vivo two-photon calcium imaging of neuronal networks. Proc Natl Acad Sci U S A 100: 7319-7324. CrossRef Medline
Suter BA, O'Connor T, Iyer V, Petreanu LT, Hooks BM, Kiritani T, Svoboda K, Shepherd GM (2010) Ephus: multipurpose data acquisition software for neuroscience experiments. Front Neural Circuits 4:100. CrossRef Medline

Tamamaki N, Yanagawa Y, Tomioka R, Miyazaki JI, Obata K, Kaneko T (2003) Green fluorescent protein expression and colocalization with calretinin, parvalbumin, and somatostatin in the GAD67-GFP knock-in mouse. J Comp Neurol 467:60-79. CrossRef Medline

Thévenaz P, Ruttimann UE, Unser M (1998) A pyramid approach to subpixel registration based on intensity. IEEE Trans Image Process 7:27-41. CrossRef Medline

Vogelstein JT, Packer AM, Machado TA, Sippy T, Babadi B, Yuste R, Paninski L (2010) Fast nonnegative deconvolution for spike train inference from population calcium imaging. J Neurophysiol 104:3691-3704. CrossRef Medline

Woolsey TA, Van der Loos H (1970) The structural organization of layer IV in the somatosensory region (S1) of mouse cerebral cortex. Brain Res 17:205-242. CrossRef Medline

Yamashita T, Pala A, Pedrido L, Kremer Y, Welker E, Petersen CC (2013) Membrane potential dynamics of neocortical projection neurons driving target-specific signals. Neuron 80:1477-1490. CrossRef Medline

Yassin L, Benedetti BL, Jouhanneau JS, Wen JA, Poulet JF, Barth AL (2010) An embedded subnetwork of highly active neurons in the neocortex. Neuron 68:1043-1050. CrossRef Medline 